\title{
Advances in chimeric antigen receptor T- cell therapy for B-cell non-Hodgkin lymphoma
}

\author{
Zixun Yin ${ }^{1,2}$, Ya Zhang ${ }^{1,2,3,4,5,6^{*+}}$ and Xin Wang ${ }^{1,2,3,4,5,6^{*+}}$
}

\begin{abstract}
B-cell non-Hodgkin lymphoma (B-NHL) is a group of heterogeneous disease which remains incurable despite developments of standard chemotherapy regimens and new therapeutic agents in decades. Some individuals could have promising response to standard therapy while others are unresponsive to standard chemotherapy or relapse after autologous hematopoietic stem-cell transplantation (ASCT), which indicates the necessity to develop novel therapies for refractory or relapsed B-NHLs. In recent years, a novel cell therapy, chimeric antigen receptor T-cell therapy (CAR-T), was invented to overcome the limitation of traditional treatments. Patients with aggressive B-NHL are considered for CAR-T cell therapy when they have progressive lymphoma after second-line chemotherapy, relapse after ASCT, or require a third-line therapy. Clinical trials of anti-CD19 CAR-T cell therapy have manifested encouraging efficacy in refractory or relapsed B-NHL. However, adverse effects of this cellular therapy including cytokine release syndrome, neurotoxicity, tumor lysis syndrome and on-target, off-tumor toxicities should attract our enough attention despite the great anti-tumor effects of CAR-T cell therapy. Although CAR-T cell therapy has shown remarkable results in patients with B-NHL, the outcomes of patients with B-NHL were inferior to patients with acute lymphoblastic leukemia. The inferior response rate may be associated with physical barrier of lymphoma, tumor microenvironment and low quality of CAR-T cells manufactured from B-NHL patients. Besides, some patients relapsed after anti-CD19 CAR-T cell therapy, which possibly were due to limited CAR-T cells persistence, CD19 antigen escape or antigen down-regulation. Quite a few new antigen-targeted CAR-T products and new-generation CAR-T, for example, CD20-targeted CAR-T, CD79b-targeted CAR-T, CD37-targeted CAR-T, multi-antigen-targeted CAR-T, armored CAR-T and four-generation CAR-T are developing rapidly to figure out these deficiencies.
\end{abstract}

Keywords: Chimeric antigen receptor T-cell therapy, CAR-T-associated toxicities, New targets

\section{Background}

B-cell non-Hodgkin lymphoma (B-NHL) is a group of clinically heterogeneous disease including diffuse large B-cell lymphoma (DLBCL), mantle cell lymphoma (MCL), follicular lymphoma (FL) and others [1]. DLBCL is the most common kind of B-NHL, accounting for

\footnotetext{
*Correspondence: maryzhangya@gmail.com; xinw007@126.com

${ }^{\dagger}$ Ya Zhang and Xin Wang contributed equally to this work.

'Department of Hematology, Shandong Provincial Hospital, Cheeloo College

of Medicine, Shandong University, Jinan 250021, Shandong, China

Full list of author information is available at the end of the article
}

about $30-35 \%$ in all B-NHLs [2]. The standard first-line therapy is cyclophosphamide, doxorubicin, vincristine, and prednisone, with (R-CHOP) or without rituximab (CHOP). The second-line therapies consist of high-dose chemotherapy and autologous hematopoietic stem-cell transplantation (ASCT) [3]. These standard therapies have improved outcomes of patients with B-NHL. However, the outcomes of chemotherapy-refractory patients remained poor and almost one third of patients with DLBCL relapsed $[4,5]$. CAR-T therapy is a novel treatment for these patients with refractory or relapsed

(c) The Author(s). 2021 Open Access This article is licensed under a Creative Commons Attribution 4.0 International License, which permits use, sharing, adaptation, distribution and reproduction in any medium or format, as long as you give appropriate credit to the original author(s) and the source, provide a link to the Creative Commons licence, and indicate if changes were made. The images or other third party material in this article are included in the article's Creative Commons licence, unless indicated otherwise in a credit line to the material. If material is not included in the article's Creative Commons licence and your intended use is not permitted by statutory regulation or exceeds the permitted use, you will need to obtain permission directly from the copyright holder. To view a copy of this licence, visit http://creativecommons.org/licenses/by/4.0/. The Creative Commons Public Domain Dedication waiver (http://creativecommons.org/publicdomain/zero/1.0/) applies to the data made available in this article, unless otherwise stated in a credit line to the data. 
lymphoma or acute lymphoblastic leukemia (ALL) in recent years. Many clinical trials have demonstrated the efficacy of CAR-T cell therapy against B-cell lymphoma. CARs are artificial proteins containing antigen recognition domains, T-cell signaling domains and other components. Most CARs consist of four parts. Extracellular targeting domains are usually single chain variable fragments $(\mathrm{scFv})$, which composes the variable regions of heavy and light chains in antibodies [6]. A hinge or spacer, which is designed to connect scFv with transmembrane domain. Transmembrane domain is designed to assist $\mathrm{scFv}$ and intracellular signaling domain. And intracellular signaling domains, including co-stimolatory domain and T-cell activation domain, play roles on the activation and proliferation of CAR-T cells (Fig. 1) [5]. Four CAR-T cell products have been approved by the United States Food and Drug Administration (FDA) and/or European Medicines Agency (EMA): axicabtagene ciloleucel (axi-cel) for patients with refractory large B-cell lymphoma in 2017, tisagenlecleucel (tisa-cel) for refractory/relapsed ALL in 2017 and refractory/relapsed DLBCL in May 2018, brexucabtagene autoleucel (KTEX19) for patients with refractory/relapsed MCL in 2020 and breyanzi (liso-cel) for patients with refractory/relapsed DLBCL in 2021 (Table 1; Fig. 2) [7]. Patients with aggressive B-cell lymphoma are considered for antiCD19 CAR-T when they have stable or progressive lymphoma after second-line chemotherapy, relapse after ASCT, or require a third-line therapy [8]. In this review, we discuss CAR-T clinical trials on B-NHL, adverse events, limitations and new developments of CAR-T cell therapy.

\section{Clinical trials of anti-CD19 CAR-T in B-NHL}

The antigen CD19 is widely expressed on B-cell malignancies including a wide range of B-NHL. Therefore, CD19 is an optimal target for CAR-T cell therapy in B-NHL. Anti-CD19 CAR-T cells have become the most widely applied CAR-T products and achieved encouraging improvements in clinical practice. The first case report of CD19 CAR-T therapy for one patient with B-cell lymphoma was reported in 2010. There were several completed CAR-T clinical trails for B-NHL (Table 2). For instance, NCT03483688 was a phase I b study which evaluated the safety and efficacy of C-CAR011, a CD19-directed CAR-T cells, in 6 patients. NCT02132624 was a phase I/II a study which evaluated the efficacy and safety of CD19-targeted third-generation CAR- $T$ cells for refractory B-cell malignancies including B-cell lymphoma and B-cell leukemia in 15 individuals [9-12]. Besides, many CAR-T phase I and phase II clinical trials for pediatric and adult's B-cell lymphoma are under recruiting status and the majority of them are anti-CD19 CAR-T trials (Table 3) [13]. Moreover, many clinical trials are ongoing and this review will introduce some of these trials.

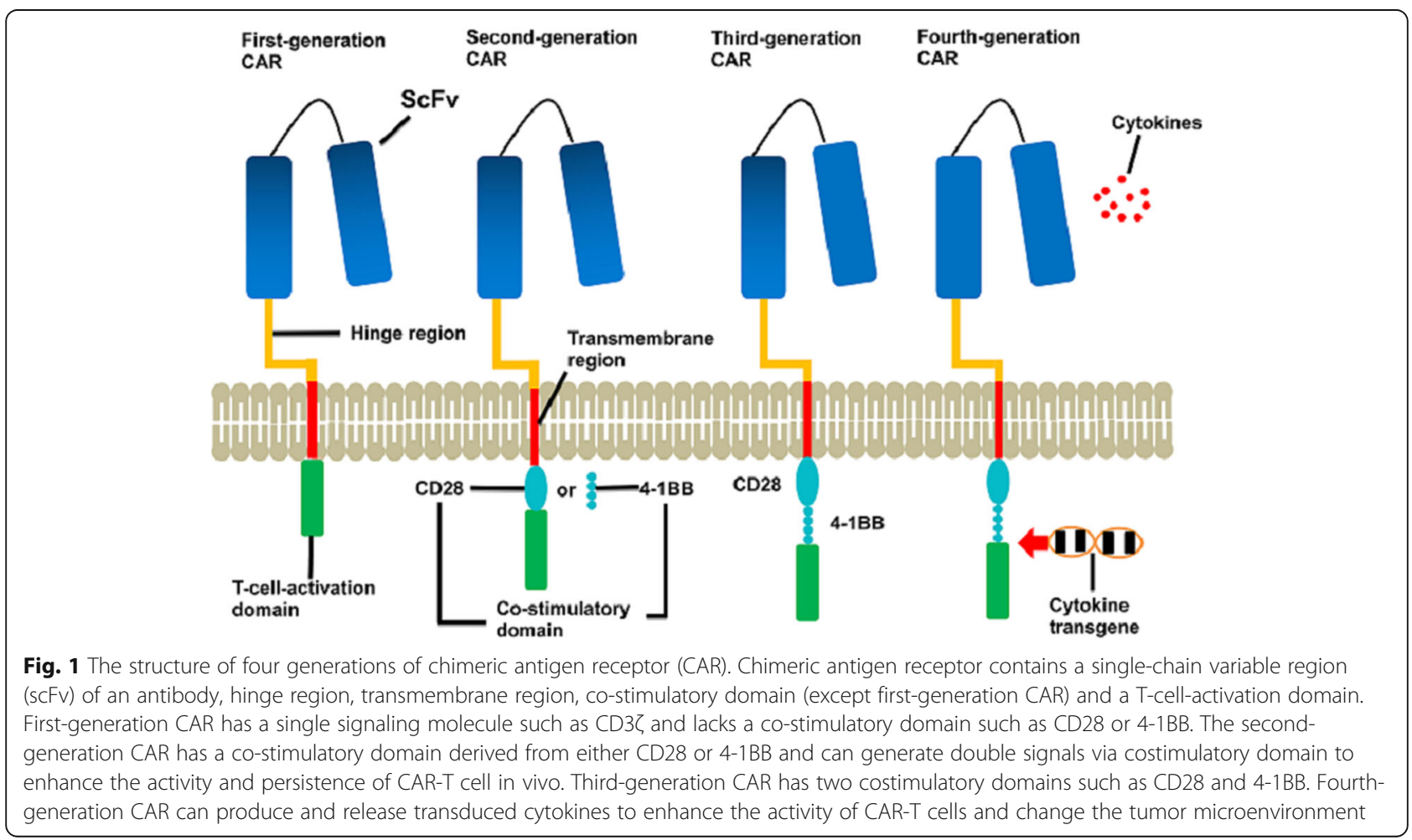


Table 1 The approved CAR-T products for B-cell non-Hodgkin lymphoma

\begin{tabular}{|c|c|c|c|c|c|c|c|c|c|c|}
\hline Product & $\begin{array}{l}\text { CAR } \\
\text { construct }\end{array}$ & $\begin{array}{l}\text { Year of } \\
\text { approval }\end{array}$ & Indication & $\begin{array}{l}\text { Bridging } \\
\text { therapy }\end{array}$ & CAR-T dose & ORR & $\begin{array}{l}\mathrm{CR} \\
\text { rate }\end{array}$ & $\begin{array}{l}\text { Median } \\
\text { PFS }\end{array}$ & $\begin{array}{l}\text { Incidence } \\
\text { of grade } 3 / \\
4 \text { CRS }\end{array}$ & $\begin{array}{l}\text { Incidence of } \\
\text { grade3/4 } \\
\text { ICANS }\end{array}$ \\
\hline $\begin{array}{l}\text { Axicabtagene } \\
\text { ciloleucel }\end{array}$ & $\begin{array}{l}\text { CD19- } \\
\text { CD28- } \\
\text { CD3द }\end{array}$ & 2017 & Refractory $\mathrm{LBCL}$ & No & $2 \times 10 \wedge 6$ cell/kg & $83 \%$ & $58 \%$ & $\begin{array}{l}5.9 \\
\text { months } \\
(3.3 \text { to } \\
15.0)\end{array}$ & $\begin{array}{l}11 \%(12 / \\
108)\end{array}$ & $32 \%$ \\
\hline Tisagenlecleucel & $\begin{array}{l}\text { CD19-4- } \\
1 \mathrm{BB}- \\
\text { CD3द }\end{array}$ & 2018 & $\begin{array}{l}\text { Relapsed or } \\
\text { refractory DLBCL } \\
\text { in adults }\end{array}$ & Yes & $\begin{array}{l}(0.1-6) \times 10 \wedge 8 \text { CAR- } \\
\text { positive viable T cells }\end{array}$ & $52 \%$ & $40 \%$ & $\begin{array}{l}8.3 \\
\text { months } \\
(5.8 \text { to } \\
11.7)\end{array}$ & $22 \%$ & $12 \%$ \\
\hline $\begin{array}{l}\text { Brexucabtagene } \\
\text { autoleucel }\end{array}$ & $\begin{array}{l}\text { CD19- } \\
\text { CD28- } \\
\text { CD3द }\end{array}$ & 2020 & $\begin{array}{l}\text { Relapsed or } \\
\text { refractory MCL }\end{array}$ & Yes & $2 \times 10 \wedge 6 \mathrm{cell} / \mathrm{kg}$ & $85 \%$ & $59 \%$ & $\begin{array}{l}4.8 \\
\text { months }\end{array}$ & $15 \%$ & $31 \%$ \\
\hline $\begin{array}{l}\text { Breyanzi } \\
\text { (Lisocabtagene } \\
\text { maraleucel) }\end{array}$ & $\begin{array}{l}\text { CD19-4- } \\
\text { 1BB - } \\
\text { CD3Z }\end{array}$ & 2021 & $\begin{array}{l}\text { Relapsed or } \\
\text { refractory } L B C L\end{array}$ & Yes & $\begin{array}{l}50 \times 10^{6}, 100 \times 10^{6} \text { and } \\
150 \times 10^{6} \text { CAR-positive } \\
T \text { cells }\end{array}$ & $73 \%$ & $53 \%$ & NR & $2 \%(6 / 269)$ & $10 \%(27 / 269)$ \\
\hline
\end{tabular}

Abbreviations: ORR objective response rate, $C R$ complete response, PFS progression-free survival, CRS cytokine release syndrome, ICANS immune effector cellassociated neurotoxicity syndrome, $L B C L$ large B-cell lymphoma, $D L B C L$ diffuse large B-celllymphoma, $M C L$ mantle-cell lymphoma

\section{KTE-X19}

KTE-X19 in relapsed or refractory MCL: MCL is a CD5+ B-NHL with high heterogeneity from indolent to highly aggressive clinical course [14, 15]. Patients with MCL have unsatisfactory prognosis after standard treatments [16]. KTE-X19 is an anti-CD19 CAR-T cell therapy designed for patients with relapsed or refractory MCL. ZUMA-2 trial was a phase II, multicenter clinical trial to evaluate the efficacy and safety of KTE-X19. Seventy-four patients were enrolled in the trial. KTEX19 was successfully manufactured for 71 patients and infused to 68 patients at a dose of $2 \times 10^{\wedge} 6$ cells $/ \mathrm{kg}$. Conditioning chemotherapy with fludarabine and cyclophosphamide was administered before infusion of KTEX19 [17]. Ninety-three percent of patients reached objective response (OR) and $67 \%$ of patients reached complete response (CR) among the first 60 treated patients. In all 74 patients, the objective response rate (ORR) was $85 \%$ and the CR rate was $59 \%$ with the median follow-up of 12.4 months. The estimated rate of progression-free survival (PFS) was $61 \%$ and overall survival rate was $83 \%$ at 12 months. All 68 patients developed at least one adverse event. The most common adverse event was pyrexia, which occurred in 94\% (64/ 68 ) of patients. The cytokine release syndrome (CRS) occurred in 61 patients. Most CRS events were grade 1 or 2. Besides, $63 \%$ of patients experienced neurologic events, with $32 \%$ having grade 3 or higher neurologic events [17].

\section{KTE-C19}

DLBCL is the most common subtype of non-Hodgkin lymphoma which accounts for almost $30 \%$ of B-NHL [18]. The multicenter ZUMA-1 phase I study evaluated the efficacy and safety of KTE-C19, which was autologous CD3//CD28-based CAR-T cell therapy. Seven patients received conditioning chemotherapy with fludarabine $\left(30 \mathrm{mg} / \mathrm{m}^{2}\right)$ and cyclophosphamide $(500 \mathrm{mg}$ / $\mathrm{m}^{2}$ ) for 3 days before infusion of KTE-C19 at a dose of $2 \times 10^{\wedge} 6$ cells $/ \mathrm{kg}$. The ORR was $71 \%(5 / 7)$ and the CR rate was $57 \%(4 / 7)$. Among all seven patients, 3 patients remained in CR at 12 months and CAR-T cells could be detected. One patient had a dose-limiting toxicity of grade 4 neurotoxicity and CRS, then the patient died of systematic inflammation. One patient experienced grade 3 or higher CRS events and four patients developed

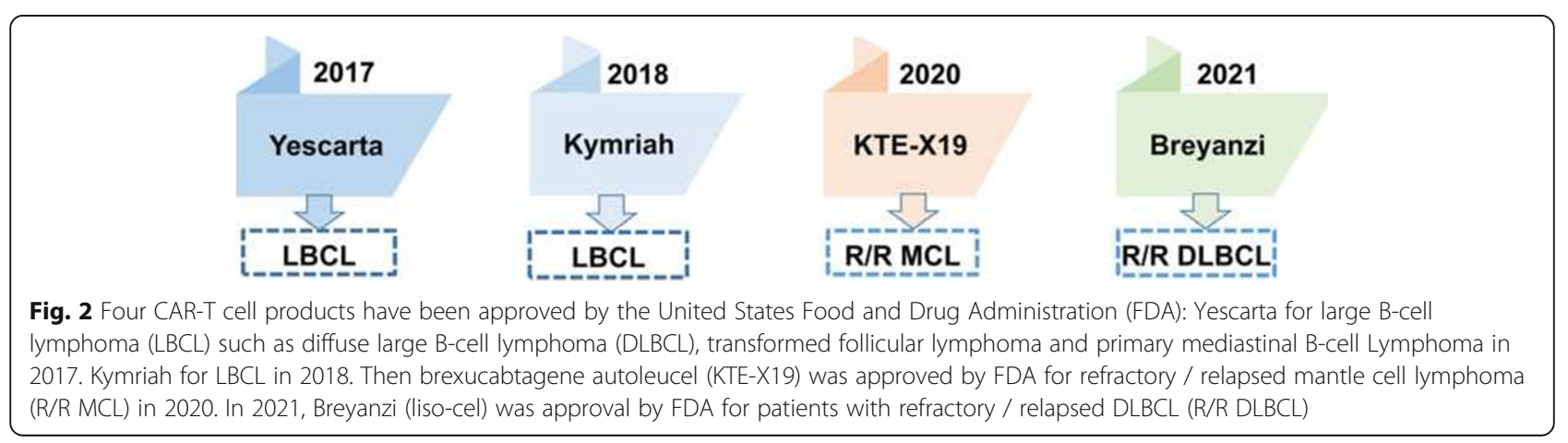


Table 2 Completed CD19 CAR-T clinical trials for B-cell non-Hodgkin lymphoma

\begin{tabular}{|c|c|c|c|c|}
\hline $\begin{array}{l}\text { NCT } \\
\text { Number }\end{array}$ & Phase & Status & Locations & Clinical outcomes \\
\hline NCT01593696 & $\begin{array}{l}\text { Phase } \\
\text { I }\end{array}$ & Completed & $\begin{array}{l}\text { National Institutes of Health Clinical Center, } 9000 \\
\text { RockvillePike, Bethesda, Maryland, United States }\end{array}$ & $\begin{array}{l}\text { The CR rate was } 59.6 \%(31 / 52) \text {. The occurrence rate of } \\
\text { serious adverse events and high grade CRS were } \\
26.9 \%(14 / 52) \text { and } 9.6 \%(5 / 52) \text {. }\end{array}$ \\
\hline NCT02132624 & $\begin{array}{l}\text { Phase } \\
\text { I/ lla }\end{array}$ & Completed & $\begin{array}{l}\text { Uppsala University Hospital, Dept of Oncology, } \\
\text { Uppsala,Sweden }\end{array}$ & $\begin{array}{l}\text { Six of the } 15 \text { patients had complete responses ( } 4 / 11 \\
\text { lymphoma and } 2 / 4 \mathrm{ALL} \text { ). Three patients developed severe } \\
\text { CRS in } 15 \text { patients and } 2 \text { patients developed high grade } \\
\text { ICANS. }\end{array}$ \\
\hline NCT02030834 & $\begin{array}{l}\text { Phase } \\
\text { lla }\end{array}$ & Completed & $\begin{array}{l}\text { Abramson Cancer Center of the University of } \\
\text { Pennsylvania,Philadelphia, Pennsylvania, United } \\
\text { States }\end{array}$ & $\begin{array}{l}\text { The objective response rate was } 64 \% \text { (18/28). Occurrence } \\
\text { rate of serious CRS and ICANS were 18\% (5/28) and 11\% } \\
(3 / 28)\end{array}$ \\
\hline NCT01626495 & $\begin{array}{l}\text { Phase } \\
\text { I /lla }\end{array}$ & Completed & $\begin{array}{l}\text { CHOP-http://www.chop.edu/service/oncology/ } \\
\text { pediatric-cancer-research/cart-19-trial.html, } \\
\text { Philadelphia, Pennsylvania, UnitedStates }\end{array}$ & $\begin{array}{l}\text { The CR rate was } 25.8 \%(16 / 62) \text { and CRi (complete } \\
\text { remission with incomplete blood count recovery) rate was } \\
61.3 \%(38 / 62) \text {. }\end{array}$ \\
\hline
\end{tabular}

Abbreviations: $C R$ complete response, CRS cytokine release syndrome, ICANS immune effector cell-associated neurotoxicity syndrome, CRi complete remission with incomplete blood count recovery, ALL acute lymphoblastic leukemia

grade 3 or higher neurotoxicities. These symptoms disappeared within 1 month [19].

\section{Axicabtagene ciloleucel}

Axicabtagene ciloleucel was one kind of autologous antiCD19 CAR-T cell which consisted of CD28 transmembrane domain and CD28 costimulatory domain for patients with B-cell lymphoma. ZUMA-1, a multicenter, phase II trial in which 111 patients with DLBCL, primary mediastinal B-cell lymphoma, or transformed FL were enrolled. Some patients were refractory to previous therapies, and some patients relapsed after ASCT. In contrast to KTE-X19 and KTE-C19, patients did not receive systemic bridging chemotherapy before infusion of CAR-T cells. A total of 101 patients received infusion of axi-cel at a dose of $2 \times 10^{\wedge} 6$ cells $/ \mathrm{kg}$. In 77 patients with DLBCL, 38 patients achieved CR and 25 patients reached partial response (PR). In other 24 patients with primary mediastinal B-cell lymphoma or transformed FL, 17 patients reached CR and 3 patients achieved PR at a minimum of 6 months of follow-up [20]. The ORR was 82 and $54 \%$ of patients achieved CR. Grade 3 or higher adverse events accounted for almost 95\% in all adverse events. The most common symptoms were pyrexia ( $85 \%$ of patients). CRS occurred in 94 patients ( $93 \%$ of patients) and most were grade 1 or 2 . Sixty-five patients (64\% of patients) developed neurotoxicity and the majority of these patients developed grade 1 or 2 neurologic events. A total of 101 patients were followed up for a median of 27.1 months. The ORR was $83 \%$ and the CR rate was $58 \%$. The incidence of adverse events was similar to that in previous reports. Grade 3 or higher CRS occurred in 12 patients (11\% of patients) and 35 patients (32\% of patients) developed grade 3 or higher neurotoxicity [21]. Besides, clinical trials of axicabtagene ciloleucel for patients with FL have demonstrated encouraging results recently. Eighty patients with FL were enrolled in the clinical trial. The ORR was $95 \%$ and CR rate was $81 \%$. Grade 3 or higher CRS occurred in $7 \%$ of the patients and the incidence of grade 3 or higher neurologic adverse events was $15 \%$.

\section{Hu19-CD828Z}

Clinical trial of FMC63-28Z had shown that neurologic toxicity was a more vital clinical problem than CRS [22]. Hu19-CD828Z, a new developed anti-CD19 CAR, was designed with a scFv from a fully-human anti-CD19 monoclonal antibody. FMC63-28Z (axi-cel), however, had the murine $\mathrm{scFv}$ [23]. The clinical trial evaluated the efficacy and safety of Hu19-CD828Z. Patients received conditioning chemotherapy with fludarabine $\left(30 \mathrm{mg} / \mathrm{m}^{2}\right)$ and cyclophosphamide $\left(500 \mathrm{mg} / \mathrm{m}^{2}\right)$ for 3 days. Then they were administered with $\mathrm{Hu} 19-\mathrm{CD} 828 \mathrm{Z}$ at 3 target doses: $0.66 \times 10^{\wedge} 6, \quad 2 \times 10^{\wedge} 6$ and $6 \times 10^{\wedge} 6$ cells $/ \mathrm{kg}$. Twenty patients with B-cell lymphoma who received previous treatments were enrolled in the trial. Incidence of neurologic events in clinical trial of Hu19-CD828Z was lower than that in clinical trial of FMC63-28Z. The occurrence of grade 2 or higher neurotoxicity of Hu19CD828Z and FMC63-28Z were 20 and 77\%, respectively. Besides, the incidence of grade 3 or higher neurologic events of Hu19-CD828Z and FMC63-28Z were 5 and $50 \%$, respectively. These results may indicate the higher safety of Hu19-CD828Z. Furthermore, serum levels of immunological proteins such as IL-2, TNF- $\alpha$ and IFN- $\gamma$ were lower in patients who received Hu19-CD828Z T cells than that in patients who received FMC63-28Z T cells. Naive and central memory (CM) T cells had more proliferation potential than effector memory and $\mathrm{T}$ effector memory $\mathrm{T}$ cells. And it was confirmed that there was a higher percentage of CD4+ CAR-T cells with naive or CM in Hu19-CD828Z T cells than those in FMC63-28Z. In conclusion, patients treated with Hu19-CD828Z had lower incidence of developing 
Table 3 Clinical trials of chimeric antigen receptor T-cell therapy for B-cell lymphoma

\begin{tabular}{|c|c|c|c|c|c|c|}
\hline $\begin{array}{l}\text { NCT } \\
\text { Numberb }\end{array}$ & Conditionso & Interventiont & $\begin{array}{l}\text { P } \\
\text { Phase } \\
\text { h }\end{array}$ & Number & Dose D & Outcomes $\mathrm{O}$ \\
\hline NCT04169932 & $\begin{array}{l}\text { R/R B-cell lymphoma; } \\
\text { NHL }\end{array}$ & CD20 CAR-T & $\begin{array}{l}\text { Early } \\
\text { phase } \\
\text { I }\end{array}$ & 20 & $(1,2,4,8) \times 10 \wedge 6$ cells $/ \mathrm{kg}$ & NR \\
\hline NCT03994913 & $\mathrm{R} / \mathrm{R} \mathrm{B}-\mathrm{NHL}$ & CD19 CAR-T & $\begin{array}{l}\text { Phase I } \\
\text { Phase } \\
\text { ॥ }\end{array}$ & 78 & NR & NR \\
\hline NCT04036019 & B-cell lymphoma & CD20 CAR- T & Phase I & 12 & NR & NR \\
\hline NCT04429438 & B-cell lymphoma & $\begin{array}{l}\text { 4SCAR19 and } \\
\text { 4SCAR20/22/70/ } \\
\text { PSMA } 13 / 79 b / G D 2\end{array}$ & $\begin{array}{l}\text { Phase I } \\
\text { Phase } \\
\text { ॥ }\end{array}$ & 11 & NR & NR \\
\hline NCT04381741 & DLBCL & $\begin{array}{l}\text { CD19 CAR-T plus } \\
\text { PD1 monoclonal } \\
\text { antibody }\end{array}$ & Phase I & 24 & $\begin{array}{l}(1,2,3) \times \\
10^{\wedge} 6 \text { cells/kg plus } 200 \mathrm{mg} \text { Tislelizumab every } \\
3 \text { weeks for } 6 \text { times }\end{array}$ & NR \\
\hline NCT04260932 & B-cell lymphoma & $\begin{array}{l}\text { CD19/CD20 Dual- } \\
\text { CAR-T }\end{array}$ & Phase I & 12 & Escalated dose of $(1-6) \times 10^{\wedge} 6$ cells $/ \mathrm{kg}$ & NR \\
\hline NCT03929107 & B-cell lymphoma & $\begin{array}{l}\text { IL-7 and chemokine } \\
\text { ligand 19- } \\
\text { expressing CD19- } \\
\text { CAR-T cells }\end{array}$ & $\begin{array}{l}\text { Phase } \\
\|\end{array}$ & 80 & NR & NR \\
\hline NCT03854994 & B-cell lymphoma; B-ALL & CD19 CAR-T Cells & Phase I & 10 & $(1-5) \times 10 \wedge 6$ cells $/ \mathrm{kg}$ & NR \\
\hline NCT04316624 & DLBCL & C-CAR066 & Phase I & 10 & 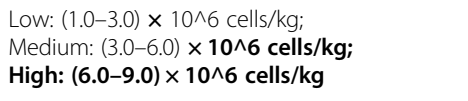 & NR \\
\hline NCT04240808 & $\mathrm{NHL}$ & UCD19 CAR T Cells & Phase I & 20 & NR & NR \\
\hline NCT04539444 & R/R NHL & CD19/22 CART & $\begin{array}{l}\text { Phase } \\
\|\end{array}$ & 20 & $\begin{array}{l}\text { 3-day split-dose regimen at dose of }(0.5-2) \times \\
10^{\wedge} \mathbf{6} \text { cells } \mathbf{k g}\end{array}$ & NR \\
\hline NCT03881761 & B-cell lymphoma & $\begin{array}{l}\text { CD19/CD20 } \\
\text { bispecific CAR-T }\end{array}$ & Phase I & 50 & $(1-3) \times 10^{\wedge} 6$ cells $/ \mathbf{k g}$ & NR \\
\hline NCT04486872 & DLBCL & $\begin{array}{l}\text { Autologous } \\
\text { humanized CD19/ } \\
\text { CD20 bispecific } \\
\text { CAR-T }\end{array}$ & Phase I & 18 & $\begin{array}{l}1.00 \times 10^{\wedge} 6 \text { cells } / \mathrm{kg}, 3.00 \times 10^{\wedge} 6 \text { cells } / \mathrm{kg} \\
\text { or } 5.00 \times 10^{\wedge} 6 \text { cells } / \mathrm{kg}\end{array}$ & NR \\
\hline NCT04257578 & $\begin{array}{l}\text { B-NHL; DLBCL; High } \\
\text { grade B-cell lymphoma; } \\
\text { PMBCL; tFL }\end{array}$ & $\begin{array}{l}\text { Axicabtagene } \\
\text { Ciloleucel }\end{array}$ & $\begin{array}{l}\text { Phase I } \\
\text { Phase } \\
\text { ॥ }\end{array}$ & 20 & NR & NR \\
\hline NCT03391726 & B-cell lymphoma & CD19 CAR-T & $\begin{array}{l}\text { Phase } \\
\text { II }\end{array}$ & 20 & NR & NR \\
\hline NCT04416984 & B-cell lymphoma & ALLO-647 & $\begin{array}{l}\text { Phase I } \\
\text { Phase } \\
\text { ॥ }\end{array}$ & 120 & NR & NR \\
\hline NCT03103971 & $\begin{array}{l}\text { B-ALL; DLBCL; PMBL; R/R } \\
\text { B-NHL }\end{array}$ & CD19 CAR-T & Phase I & 73 & NR & NR \\
\hline NCT03287817 & $\begin{array}{l}\text { DLBCL; } \\
\text { R/R DLBCL }\end{array}$ & AUTO3 & $\begin{array}{l}\text { Phase I } \\
\text { Phase } \\
\text { ॥ }\end{array}$ & 171 & $(50-900) \times 10 \wedge 6$ cells & NR \\
\hline NCT04049513 & $\begin{array}{l}\text { B-NHL; DLBCL; PMBCL; } \\
\text { tFL; FL; MCL }\end{array}$ & WZTLO02-1 & Phase I & 12 & Starting dose of $5 \times 10^{\wedge} 4$ cells $/ \mathbf{k g}$ & NR \\
\hline NCT04432506 & $\begin{array}{l}\text { R/R DLBCL; R/R high } \\
\text { grade B-cell lymphoma; } \\
\text { R/R PMBCL; R/R tFL }\end{array}$ & $\begin{array}{l}\text { Axicabtagene } \\
\text { Ciloleucel }\end{array}$ & Phase I & 20 & NR & NR \\
\hline NCT04532268 & ALL; B-NHL & $\begin{array}{l}\text { Humanized CD19 } \\
\text { CAR-T cells }\end{array}$ & $\begin{array}{l}\text { Early } \\
\text { phase } \\
1\end{array}$ & 72 & NR & NR \\
\hline NCT03932955 & Lymphoma & $\begin{array}{l}\text { MC-19PD1 CAR-T } \\
\text { cells }\end{array}$ & Phase I & 15 & NR & NR \\
\hline NCT04191941 & B-NHL; B-ALL; MM & Novel CAR-T & Phase I & 9 & NR & NR \\
\hline NCT04007029 & $\begin{array}{l}\text { CLL; R/R DLBCL; FL; } \\
\text { MCL; PMBCL; SLL }\end{array}$ & CAR-T & Phase I & 24 & NR & NR \\
\hline NCT04163302 & B-cell lymphoma & $\begin{array}{l}\text { CD19-PD1-CAR-T } \\
\text { Cell }\end{array}$ & $\begin{array}{l}\text { Phase } \\
\text { ॥ }\end{array}$ & 30 & NR & NR \\
\hline
\end{tabular}


Table 3 Clinical trials of chimeric antigen receptor T-cell therapy for B-cell lymphoma (Continued)

\begin{tabular}{|c|c|c|c|c|c|c|}
\hline $\begin{array}{l}\text { NCT } \\
\text { Numberb }\end{array}$ & Conditionso & Interventiont & $\begin{array}{l}\text { P } \\
\text { Phase } \\
\text { h }\end{array}$ & Number & Dose D & Outcomes 0 \\
\hline NCT04215016 & $\begin{array}{l}\text { R/R DLBCL Patients With } \\
\text { Either CD19 or CD20 } \\
\text { Positive }\end{array}$ & $\begin{array}{l}\text { Autologous } \\
\text { humanized CD19/ } \\
\text { CD20 bispecific } \\
\text { CAR-T }\end{array}$ & Phase I & 18 & $\begin{array}{l}\text { The first dose is } 1.0 \times 10^{\wedge} 6 \text { cells } / \mathbf{k g} \text {, the } \\
\text { second dose is } 3.0 \times 10^{\wedge} 6 \text { cells } / \mathrm{kg} \text { and the } \\
\text { third dose is } 8.0 \times 10^{\wedge} 6 / \mathrm{kg} \text {. }\end{array}$ & NR \\
\hline NCT03664635 & $\mathrm{R} / \mathrm{R} \mathrm{B}-\mathrm{NHL}$ & MB-CART20.1 & $\begin{array}{l}\text { Phase I } \\
\text { Phase } \\
\text { ॥ }\end{array}$ & 19 & $\begin{array}{l}\text { Safety dose level: } 1 \times 10^{\wedge} 5 \text { cells } / \mathbf{k g} \\
\text { Dose level } 1: 1 \times 10^{\wedge} 6 \text { cells } / \mathbf{k g} \\
\text { Dose level } 2: 3 \times 10^{\wedge} 6 \text { cells } / \mathbf{k g}\end{array}$ & NR \\
\hline NCT04088890 & B-ALL; B-NHL; DLBCL & CD22 CAR-T & Phase I & 95 & $\begin{array}{l}\text { ALL: } 3 \times 10^{\wedge} 5 \text { cells } / \mathrm{kg}( \pm 20 \%) ; \text { B-NHL: } 1 \times \\
10^{\wedge} 6 \text { cells } / \mathrm{kg}, 3 \times 10^{\wedge} 6 \text { cells } / \mathrm{kg} \text { and } 1 \times \\
10^{\wedge} 7 \text { cells } / \mathrm{kg}\end{array}$ & NR \\
\hline NCT03366324 & $\begin{array}{l}\text { ALL; } \\
\text { B-cell lymphoma }\end{array}$ & $\begin{array}{l}\text { Second generation } \\
\text { CAR-T cells }\end{array}$ & $\begin{array}{l}\text { Phase I } \\
\text { Phase } \\
\text { ॥l }\end{array}$ & 20 & NR & NR \\
\hline NCT03277729 & $\begin{array}{l}\text { R/R B-NHL; CLL; R/R } \\
\text { DLBCL; Recurrent FL; Re- } \\
\text { current MCL; Recurrent } \\
\text { MZL }\end{array}$ & CAR-T & $\begin{array}{l}\text { Phase I } \\
\text { Phase } \\
\text { II }\end{array}$ & 30 & NR & NR \\
\hline NCT04532281 & $\mathrm{ALL} ; \mathrm{NHL}$ & CD19 CAR-T & $\begin{array}{l}\text { Early } \\
\text { phase } \\
\text { I }\end{array}$ & 120 & NR & NR \\
\hline NCT03398967 & B-cell lymphoma & $\begin{array}{l}\text { Dual specificity } \\
\text { CD19 and CD20 or } \\
\text { CD22 CAR-T Cells }\end{array}$ & $\begin{array}{l}\text { Phase I } \\
\text { Phase } \\
\text { ॥l }\end{array}$ & 80 & NR & NR \\
\hline NCT02965092 & $\begin{array}{l}\text { ALL; } \\
\text { B-cell lymphoma }\end{array}$ & $\begin{array}{l}\text { Second generation } \\
\text { CAR-T cells }\end{array}$ & $\begin{array}{l}\text { Phase I } \\
\text { Phase } \\
\text { ॥ }\end{array}$ & 80 & $(0.89-4.01) \times 10^{\wedge} 6$ CAR-T cells $/ \mathrm{kg}$ & $\begin{array}{l}\text { Median overall survival (OS) was } 16.1 \\
\text { months. The } 6 \text {-month and } 12 \text {-month } \\
\text { OS rates were } 69.727 \text { and } 64.028 \% \text {. }\end{array}$ \\
\hline NCT02963038 & B-cell lymphoma & $\begin{array}{l}\text { Autologous CD19- } \\
\text { targeting CAR T }\end{array}$ & $\begin{array}{l}\text { Phase I } \\
\text { Phase } \\
\text { ॥ }\end{array}$ & 10 & NR & NR \\
\hline NCT03383952 & B-cell lymphoma & ICAR19 CAR-T cells & Phase I & 20 & NR & NR \\
\hline NCT04007978 & B-cell lymphoma; ALL & $\begin{array}{l}\text { Third generation } \\
\text { CAR- T }\end{array}$ & Phase I & 50 & NR & NR \\
\hline NCT04532203 & $\mathrm{ALL} ; \mathrm{NHL}$ & CAR-T cells & $\begin{array}{l}\text { Early } \\
\text { phase } \\
\text { I }\end{array}$ & 72 & NR & NR \\
\hline NCT04603872 & $\begin{array}{l}\text { R/R MM; R/R ALL; R/R } \\
\text { NHL }\end{array}$ & $\begin{array}{l}\text { CD19/BCMA CAR T- } \\
\text { cells }\end{array}$ & $\begin{array}{l}\text { Early } \\
\text { phase } \\
\text { I }\end{array}$ & 120 & NR & NR \\
\hline NCT03939026 & $\begin{array}{l}\text { R/R Large B-Cell Lymph- } \\
\text { oma; R/R FL }\end{array}$ & ALLO-647 & Phase I & 54 & NR & NR \\
\hline NCT04008251 & $\begin{array}{l}\text { ALL; } \\
\text { B-cell lymphoma }\end{array}$ & $\begin{array}{l}\text { Second generation } \\
\text { humanized CAR-T }\end{array}$ & Phase I & 10 & NR & NR \\
\hline NCT03118180 & Lymphoma & CD19 CAR-T & $\begin{array}{l}\text { Phase I } \\
\text { Phase } \\
\text { ॥ }\end{array}$ & 50 & NR & NR \\
\hline NCT02650414 & B-cell lymphoma & CD22 CAR-T & Phase I & 15 & 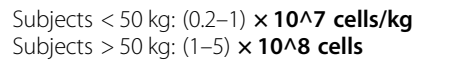 & NR \\
\hline NCT04317885 & $\mathrm{B}-\mathrm{NHL}$ & $\begin{array}{l}\text { CD19/CD20- } \\
\text { directed CAR-T cells }\end{array}$ & Phase I & 25 & NR & NR \\
\hline NCT03166878 & B-cell lymphoma & UCART019 & $\begin{array}{l}\text { Phase I } \\
\text { Phase } \\
\text { ॥ }\end{array}$ & 80 & $\begin{array}{l}\text { Day 0: } 10 \% \text { of total dose. Day 1: } 30 \% \text { of total } \\
\text { dose if patient is stable. Day 2: } 60 \% \text { of total } \\
\text { dose if patient is stable. }\end{array}$ & NR \\
\hline NCT03720457 & $\mathrm{DLBCL} ; \mathrm{FL}$ & CD19 CAR-T & Phase I & 18 & NR & NR \\
\hline NCT03559439 & B-cell lymphoma; B-ALL & CD19 CAR T & Phase I & 9 & $\begin{array}{l}\text { Low: } 1 \times 10^{\wedge} 5 \text { cells } / \mathrm{kg} ; \text { Medium: } 2 \times 10^{\wedge} 6 \\
\text { cells } / \mathrm{kg} ; \mathrm{High:} 6 \times 10^{\wedge} 6 \text { cells } / \mathrm{kg}\end{array}$ & NR \\
\hline NCT04088864 & B-cell lymphoma; ALL & $\begin{array}{l}\text { Autologous CD22 } \\
\text { CAR T }\end{array}$ & Phase I & 52 & $\begin{array}{l}\text { R/R B-ALL: } 1 \times 10^{\wedge} 6 \text { cells/kg }( \pm 20 \%) \text {. } \\
\text { Lymphoma: } 1 \times 10^{\wedge} 6 \text { cells/kg }( \pm 20 \%) .\end{array}$ & NR \\
\hline NCT03696784 & B-cell lymphoma & iC9-CAR19 T cells & Phase I & 30 & $(1-2) \times 10 \wedge 6$ cells $/ \mathbf{k g}$ & NR \\
\hline NCT04204161 & $\begin{array}{l}\text { R/R ALL; } \\
\text { B-cell lymphoma }\end{array}$ & CAR-T19/CAR-T22 & Phase I & 30 & $\begin{array}{l}\text { The recommand dose: } 1 \times 10^{\wedge} 5 / \mathrm{kg}- \\
2.5 \times 10^{\wedge} 8 / \mathrm{kg}\end{array}$ & NR \\
\hline
\end{tabular}


Table 3 Clinical trials of chimeric antigen receptor T-cell therapy for B-cell lymphoma (Continued)

\begin{tabular}{|c|c|c|c|c|c|c|}
\hline $\begin{array}{l}\text { NCT } \\
\text { Numberb }\end{array}$ & Conditionso & Interventiont & $\begin{array}{l}\text { P } \\
\text { Phase } \\
\text { h }\end{array}$ & Number & Dose D & Outcomes 0 \\
\hline NCT03853616 & $\begin{array}{l}\text { ALL; } \\
\text { B-cell lymphoma; R/R } \\
\text { CLL }\end{array}$ & MB-CART19.1 & $\begin{array}{l}\text { Phase I } \\
\text { Phase } \\
\text { ॥ }\end{array}$ & 48 & $1 \times 10 \wedge 5 / \mathrm{kg}-3 \times 10 \wedge 6 / \mathrm{kg}$ & NR \\
\hline NCT03881774 & B-cell lymphoma & CAR-T cells & Phase I & 20 & $(0.5-3) \times 10^{\wedge} 6 / \mathrm{kg}$ & NR \\
\hline NCT04176913 & DLBCL; FL; MCL; SLL & $\begin{array}{l}\text { LUCAR-20S CAR-T } \\
\text { cells }\end{array}$ & Phase I & 41 & NR & NR \\
\hline NCT04156243 & B-cell lymphoma & CD19 CAR T cells & $\begin{array}{l}\text { Early } \\
\text { phase } \\
1\end{array}$ & 20 & NR & NR \\
\hline NCT04089215 & $\mathrm{NHL} ; \mathrm{DLBCL} ; \mathrm{FL}$ & CD19 CAR-T & $\begin{array}{l}\text { Phase } \\
\|\end{array}$ & 82 & $1.0 \times 10^{\wedge} 8$ and $1.5 \times 10^{\wedge} 8$ cells & Three month ORR: 60.3\% \\
\hline NCT04205838 & $\begin{array}{l}\text { DLBCL; High grade B- } \\
\text { cell lymphoma; R/R tFL; } \\
\text { R/R PMBCL }\end{array}$ & $\begin{array}{l}\text { Axicabtagene } \\
\text { Ciloleucel }\end{array}$ & $\begin{array}{l}\text { Phase } \\
\|\end{array}$ & 36 & NR & NR \\
\hline NCT04464200 & $\begin{array}{l}\text { DLBCL; PMBCL; } \\
\text { tFL; CLL; MZL; WM; } \\
\text { Burkitt's lymphoma; } \\
\text { Primary CNS lymphoma }\end{array}$ & $\begin{array}{l}19(T 2) 28 z 1 \times x \text { CAR T } \\
\text { cells }\end{array}$ & Phase I & 60 & $\begin{array}{l}\text { Planned flat-dose levels: }(25,50,100,150 \text {, } \\
200) \times 10^{\wedge} 6 \text { cells; } \\
\text { De-escalation dose: } 12.5 \times 10^{\wedge} 6 \text { cells. }\end{array}$ & NR \\
\hline NCT04545762 & $\begin{array}{l}\text { Refractory NHL; Burkitt } \\
\text { lymphoma; MCL; FL; } \\
\text { PMBCL; } \\
\text { DLBCL; SLL }\end{array}$ & CD19 CAR-T cells & Phase I & 36 & Starting dose: $5 \times 10 \wedge 5$ cells $/ \mathrm{kg}$ & NR \\
\hline NCT03999697 & $\begin{array}{l}\text { DLBCL; FL; MCL; Plasma } \\
\text { cell neoplasm }\end{array}$ & CD22 CAR-T & Phase I & 10 & NR & NR \\
\hline NCT04214886 & $\begin{array}{l}\text { B-ALL; } \\
\text { B-cell lymphoma }\end{array}$ & CD19-CD34 CAR-T & Phase I & 24 & $\begin{array}{l}1 \times 10 \wedge 6 \text { cells } / \mathrm{kg}( \pm 20 \%) \text { to } 2 \times 10 \wedge 6 \text { cells/ } \\
\mathrm{kg}\end{array}$ & NR \\
\hline NCT03666000 & $\mathrm{NHL} ; \mathrm{B}-\mathrm{ALL}$ & PBCAR0191 & $\begin{array}{l}\text { Phase I } \\
\text { Phase } \\
\text { ॥ }\end{array}$ & 92 & $\begin{array}{l}\text { Starting dose: } 3 \times 10 \wedge 5 \text { cells } / \mathrm{kg} ; \\
\text { Subsequent dose groups: escalating doses to } \\
\text { a maximum dose of } 9 \times 10^{\wedge} 6 \text { cells } / \mathrm{kg} \text {. }\end{array}$ & NR \\
\hline NCT02772198 & B-ALL; B-NHL & CD19 CAR T cells & $\begin{array}{l}\text { Phase I } \\
\text { Phase } \\
\text { ॥ }\end{array}$ & 300 & NR & $\begin{array}{l}\text { ORR was } 84 \%(30 / 36) \text { in } A L L \text { and } \\
62 \%(32 / 52) \text { in NHL. }\end{array}$ \\
\hline NCT04156178 & B-cell lymphoma & CD20-CD19 CAR-T & $\begin{array}{l}\text { Early } \\
\text { phase } \\
\text { l }\end{array}$ & 12 & NR & NR \\
\hline NCT03743246 & $\begin{array}{l}\text { Precursor cell } \\
\text { lymphoblastic leukemia- } \\
\text { lymphoma; B-cell } \\
\text { lymphoma }\end{array}$ & JCAR017 & $\begin{array}{l}\text { Phase I } \\
\text { Phase } \\
\text { ॥ }\end{array}$ & 121 & $0.05 \times 10^{\wedge} 6-0.75 \times 10 \wedge 6$ cells $/ \mathrm{kg}$ & NR \\
\hline NCT03676504 & $\begin{array}{l}\mathrm{ALL} ; \mathrm{CLL} ; \mathrm{DLBCL} ; \mathrm{FL} ; \\
\mathrm{MCL}\end{array}$ & CD19 CAR T Cells & $\begin{array}{l}\text { Phase I } \\
\text { Phase } \\
\text { ॥ }\end{array}$ & 48 & $1 \times 10 \wedge 6$ cells $/ \mathrm{m} \wedge 2$ to $20 \times 10 \wedge 7$ cells $/ \mathrm{m}^{\wedge} 2$ & NR \\
\hline NCT03448393 & $\begin{array}{l}\text { ALL; } \\
\text { B-cell lymphoma; B-NHL }\end{array}$ & $\begin{array}{l}\text { CD19/CD22 CAR T- } \\
\text { Cells }\end{array}$ & Phase I & 89 & $\begin{array}{l}1 \times 10 \wedge 5 \text { cells } / \mathrm{kg}(+/-20 \%) ; 3 \times 10 \wedge 5 \text { cells/ } \\
\mathrm{kg}(+/-20 \%) ; 1 \times 10 \wedge 6 \mathrm{cell} / \mathrm{s} / \mathrm{kg} ; 3 \times 10^{\wedge} 6 \\
\text { cells } / \mathrm{kg}(+/-20 \%) ; 1 \times 10 \wedge 7 \mathrm{cell} / \mathrm{sg}(+/- \\
20 \%)\end{array}$ & NR \\
\hline NCT04186520 & B-NHL; MCL & CAR-T & $\begin{array}{l}\text { Phase I } \\
\text { Phase } \\
\text { ॥ }\end{array}$ & 32 & $2.5 \times 10 \wedge 6$ cells $/ \mathrm{kg}$ & NR \\
\hline NCT02631044 & $\begin{array}{l}\text { NHL; DLBCL; FL; MCL; } \\
\text { PMBCL }\end{array}$ & JCAR017 & Phase I & 314 & $\begin{array}{l}50 \times 10 \text { CAR-T cells [one or two doses], } \\
100 \times 10 \text { CAR-T cells, and } 150 \times 10 \text { CAR-T } \\
\text { cells. }\end{array}$ & $\begin{array}{l}\text { ORR was } 73 \% \text { and CR rate was 53\% } \\
\text { among } 256 \text { patients with B-NHL. }\end{array}$ \\
\hline NCT03744676 & $\begin{array}{l}\text { B-NHL; } \\
\text { B-cell lymphoma; } \\
\text { DLBCL }\end{array}$ & $\begin{array}{l}\text { lisocabtagene } \\
\text { maraleucel }\end{array}$ & $\begin{array}{l}\text { Phase } \\
\|\end{array}$ & 80 & NR & NR \\
\hline NCT02706405 & $\mathrm{DLBCL} ; \mathrm{PMBCL}$ & JCAR014 & Phase I & 42 & NR & NR \\
\hline NCT04226989 & $\mathrm{ALL} ; \mathrm{NHL}$ & CT-RD06 & $\begin{array}{l}\text { Early } \\
\text { phase } \\
\text { I }\end{array}$ & 72 & NR & NR \\
\hline NCT04314843 & B-cell lymphoma & $\begin{array}{l}\text { Axicabtagene } \\
\text { Ciloleucel }\end{array}$ & $\begin{array}{l}\text { Phase I } \\
\text { Phase } \\
\text { II }\end{array}$ & 36 & NR & NR \\
\hline
\end{tabular}


Table 3 Clinical trials of chimeric antigen receptor T-cell therapy for B-cell lymphoma (Continued)

\begin{tabular}{|c|c|c|c|c|c|c|}
\hline $\begin{array}{l}\text { NCT } \\
\text { Numberb }\end{array}$ & Conditionso & Interventiont & $\begin{array}{l}\text { P } \\
\text { Phase } \\
\text { h }\end{array}$ & Number & Dose D & Outcomes $\mathrm{O}$ \\
\hline NCT03497533 & $\mathrm{B}-\mathrm{NHL}$ & TriCAR-T-CD19 & $\begin{array}{l}\text { Phase I } \\
\text { Phase } \\
\text { ॥ }\end{array}$ & 6 & $(0.5-1) \times 10 \wedge 6$ CAR-T cells $/ \mathrm{kg}$ & NR \\
\hline NCT03720496 & $\mathrm{B}-\mathrm{NHL}$ & CD19-TriCAR-T & Phase I & 6 & $(0.1-1) \times 10^{\wedge} 6$ cells $/ \mathrm{kg}$ & NR \\
\hline NCT03105336 & FL; MZL; Indolent NHL & $\begin{array}{l}\text { Axicabtagene } \\
\text { ciloleucel }\end{array}$ & $\begin{array}{l}\text { Phase } \\
\|\end{array}$ & 160 & NR & NR \\
\hline NCT03310619 & $\mathrm{NHL} ; \mathrm{DLBCL} ; \mathrm{FL}$ & JCAR017 & $\begin{array}{l}\text { Phase I } \\
\text { Phase } \\
\|\end{array}$ & 75 & $\begin{array}{l}50 \times 10 \wedge 6 \text { CAR-T cells; } 100 \times 10 \wedge 6 \text { CAR-T } \\
\text { cells. }\end{array}$ & NR \\
\hline
\end{tabular}

Abbreviations: $C A R$ chimeric antigen receptor, ORR objective response rate, $C R$ complete response, $D L B C L$ diffuse large B-cell lymphoma, $B$ - $A L L$ B-cell acute lymphoblastic leukemia, $N H L$ non-Hodgkin lymphoma, $B-N H L$ B-cell non-Hodgkin lymphoma, $R / R B-N H L$ refractory/relapsed B-cell non-Hodgkin lymphoma, $P M B C L$ primary mediastinal large B-cell lymphoma, $F L$ follicular lymphoma, $t F L$ transformed follicular lymphoma, $R / R t F L$ refractory/relapsed transformed follicular lymphoma, MCL mantle cell lymphoma, MM multiple myeloma, SLL small lymphocytic lymphoma, CLL chronic lymphocytic leukemia, MZL marginal zone lymphoma, WM Waldenstrom macroglobulinemia

neurologic events, lower levels of immunological proteins in serum, higher proliferation potentials of $\mathrm{T}$ cells and longer-term persistence of CAR-T cells [24].

\section{Tisagenlecleucel}

There was a multicenter, international phase II study of tisagenlecleucel involving adult patients who cannot receive ASCT for some reasons or had poor prognosis after ASCT [25]. Tisagenlecleucel consisted of CD8 transmembrane domain and 4-1BB costimulatory domain. In this clinical trial, 165 patients were enrolled and 111 received an infusion of tisagenlecleucel at a median dose of $3.0 \times 10^{\wedge} 8 \mathrm{~T}$ cells (range $0.1 \times 10^{\wedge} 8$ to $6.0 \times$ $\left.10^{\wedge} 8\right)$. Ninety-two percent of the patients received bridging therapy before infusion of CAR-T cells. Among 93 patients who had 3 months or more follow-up, the best ORR was $52 \%$. Forty percent of patients received CR and $12 \%$ of patients reached PR. Thirty-eight percent of patients achieved a response and the CR rate was $32 \%$ at 3 months follow-up. Thirty percent of patients remained in $\mathrm{CR}$ at 6 months. At 12 months follow-up, the overall survival rate was $49 \%$ among all patients who received infusion of CAR-T cells and $95 \%$ of those patients still remained in CR. The most common adverse events was CRS, which occurred in $58 \%$ of patients. Fourteen percent of patients received tocilizumab and 10\% of patients received both tocilizumab and glucocorticoids for CRS management. Neurologic events occurred in $21 \%$ of patients. Among these patients, nine patients had grade 3 or 4 neurologic events and CRS at the same time [25].

\section{Lisocabtagene maraleucel}

Lisocabtagene maraleucel is an autologous anti-CD19 CAR-T cell product with a CD28 transmembrane domain and 4-1BB co-stimulatory domain for patients with relapsed or refractory large B-cell lymphoma. Lisocabtagene maraleucel had a defined 1:1 ratio of CD4:CD8 $\mathrm{T}$ cells. There was a multicentre study of lisocabtagene maraleucel, named as TRANSCEND, to evaluate the efficacy and safety of lisocabtagene maraleucel. A total of 344 patients were enrolled. Fifty patients failed to receive CAR-T cells for some reasons among them. Fifty-nine percent of the patients received bridging therapy before infusion. Patients were assigned to one of three target dose levels $\left(50 \times 10^{6}, 100 \times 10^{6}\right.$ and $150 \times 10^{6}$ CAR-T cells). Twenty-five patients received non-conforming CAR-T cells and 269 patients succeeded in infusion of at least one dose of CAR-T cells among the remaining 294 patients. However, thirteen patients were excluded from 269 patients for no PET-positive disease. In the end, there were 256 patients included in the efficacyevaluable set. One hundred and eighty-six (73\%) patients reached OR, with $53 \%$ of patients in CR. CRS occurred in 113 patients (42\%) and grade 3 or 4 CRS occurred in $6(2 \%)$ patients. Moreover, 27 (10\%) patients experienced grade 3 or 4 neurotoxicities [26].

\section{Discussion of clinical trials}

Clinical trials of CAR-T have demonstrated durable remission. However, the response rates were different. The construct of CAR-T product may contribute to the difference in response rates. Axicabtagene ciloleucel consists of CD28 transmembrane domain and CD28 costimulatory domain [20]. Tisagenlecleucel consists of CD8 transmembrane domain and 4-1BB co-stimulatory domain [25]. And lisocabtagene maraleucel is composed of CD28 transmembrane domain and 4-1BB costimulatory domain. The ORR was 82,52 and $73 \%$, respectively. Patients who received CAR-T products with CD28 transmembrane domains tended to have higher ORR than patients who received CAR-T products with CD8 transmembrane domains in clinical trials. Besides, the bridging therapy before infusion could affectresponse rates. Patients did not receive systemic bridging therapy in ZUMA-1. The ORR and CR rate were 82 and 54\%, respectively. In clinical trial of tisagenlecleucel, most 
patients received bridging therapy. The ORR and CR rate were lower than that in ZUMA-1. There was one clinical study to evaluate the impact of bridging therapy on outcomes of 148 patients with B-NHL who underwent leukapheresis for axicabtagene ciloleucel infusion. The one-year PFS rate was $40 \%$ and the overall survival rate was $65 \%$ in patients who did not receive bridging therapy. These two rates were 21 and $48 \%$ in patients who received bridging therapy [27]. However, the reasons why bridging therapy could have impact on response and survival rate in B-NHL patients treated with CAR-T cell therapy are still unclear. Moreover, host systematic inflammation and tumor burden before treatment can be determining factors for the clinical outcomes of CAR-T cell therapy [28].

\section{Chimeric antigen receptor T-cell-associated toxicities and managements}

Despite the remarkable clinical efficacy for patients with B-NHL or other B-cell malignancies, CAR-T cellassociated toxicities such as CRS can be observed in clinical trials, which limit the number of patients who are eligible for CAR-T cell therapy. CRS and immune effector cell-associated neurotoxicity syndrome (ICANS) are the two most common CAR-T cell-associated toxicities [29].

\section{CRS}

CRS is the most common adverse event of CAR-T cell therapy [30]. CRS is defined as a clinical syndrome that may occur after cell therapy due to the release of cytokines (substances secreted by immune cells) into the body's blood stream. The common clinical manifestations of CRS include fever, myalgias, headache, fatigue or other ful-like clinical presentations. Hypotension, hypoxia, coagulopathy and multiorgan dysfunction are severe symptoms of CRS. Severe symptoms are lifethreatening and patients often need vasopressors, ventilation support and other supportive treatments [31, 32]. Fever occurs firstly in the majority of patients and serves as the hallmark of CRS while the severity of CRS is usually judged by hypotension and hypoxia [33]. Abnormal indexes detected in patients with CRS include elevated C-reactive protein (CRP), ferritin, interleukin-6 (IL-6), tumor necrosis factor alpha (TNF $\alpha)$, interferon gamma (IFN $\gamma$ ), cytopenias, coagulation abnormalities, elevated liver function, and elevated creatinine. Analysis of clinical data showed that high tumor burden, high T-cell doses and high peak of T-cell expansion can increase the incidence of CRS. The severity of CRS may be associated with tumor burden, inflammatory levels, conditioning therapy and doses of CAR-T cells. CRS is triggered by inflammatory cytokines and chemokines released by CAR-T cells. The immune process begins with CAR-T recognizing and binding to targeted cells, then the activated CAR-T cells can produce effector cytokines such as IFN $\gamma$, TNF $\alpha$ and IL-2. Effector cytokines make monocytes release inflammatory cytokines such as IL-1, IL-6, IFN $\gamma$ and IL-10. These inflammatory cytokines can result in clinical manifestations of CRS mentioned above. Treatments including tocilizumab, corticosteriods, vasoactive drugs, mechanical ventilation and other supportive measures should be used for patients who developed severe CRS in time [34]. IL-6, as one inflammatory cytokine of CRS, leads to the clinical application of the IL-6 receptor inhibitor such as tocilizumab for the management of CRS [35]. Tocilizumab blocks membrane-bound as well as soluble IL-6 receptors. A retrospective analysis for patients with CRS after the treatment with CTL019 and KTE-C19 on prospective clinical trials showed that $69 \%$ of patients (31/45) in clinical trial of CTL019 had a response within 14 days of the first dose of tocilizumab. And $53 \%$ of patients $(8 / 15)$ in the clinical trial of KTEC19 received a response after treatment of tocilizumab. No tocilizumab-related adverse events were reported [36]. Corticosteriods are used in clinical experience due to the extensive effects on immune system and often used in tocilizumab-refractory cases. However, corticosteriods may influence the activation and proliferation of CAR-T cells [34]. Besides, many third-line agents such as siltuximab, cyclophosphamide and anakinra have been applied in cases of refractory CRS. Janus kinase-signal transducers and activators of transcription (JAK-STAT) pathway plays an important role on inducing biologic activity for many inflammatory cytokines and mediators. There was a phase II clinical trial of itacitinib, a JAK1 inhibitor, for the management of CRS induced by CAR-T cell therapy [37]. The clinical trial showed that itacitinib could reduce cytokines levels such as IL-6, IL-12, and IFN- $\gamma$ in murine models of inflammation. Previous researches have demonstrated that host macrophages are the main source of IL-6 after CAR-T cells infusion [38]. Itacitinib can reduce the level of IL- 6 released by macrophages and reduce cytokines production of CAR-T cells without affecting proliferation and anti-tumor activity of CAR-T cells [37]. Due to the specific role of macrophage in CRS, new therapies targeting macrophage-involved pathways such as GM-CSF and atrial natriuretic peptide (ANP) have great potential [39]. Besides, hemofiltration and plasma exchange can be used to control severe CRS in some patients which cannot be relieved by corticosteriods, tocilizumab and other treatments.

\section{ICANS}

Neurotoxicity or ICANS is the second most common toxicity related to CAR-T cell therapy. ICANS typically occurs 4 to 5 days after CAR-T treatment, lasts 5 to 10 days and can range from disorientation and aphasia to 
potentially life-threatening brain edema. A variety of symptoms can be observed ranging from early symptoms such as word-finding difficulty, confusion, headache and impaired attention to more severe presentations including damaging motor skills, seizures, descending level of consciousness, coma, cerebral edema, and death. High tumor burden, high infused doses of CAR-T cells, high-intensity lymphodepletion and preexisting neurologic complications could be the risk factors for ICANS [32]. Serum biomarker analysis showed the associations of IL-6, IL-15, IL$2 R \alpha$, and other biomarkers with grade 3 or higher CRS and ICANS. However, CAR-T cells levels and some specific cytokines, including IL-2, GM-CSF, and ferritin, were associated only with grade 3 or higher ICANS, but not severe CRS [40, 41]. Besides, baseline level of blood platelet $<60 \times 10^{9}$, mean corpuscular hemoglobin concentration $(\mathrm{MCHC})>33.2 \%$ and morphologic disease (> 5\% blasts) can also serve as predictive biomarkers for severe neurotoxicity [32]. Patients with ICANS are difficult in having good response to treatment compared to patients with CRS. As a result, patients usually need more hospitalization time and supportive care [42]. The best treatment for ICANS is still unknown nowdays. Supportive therapy can manage patients with grade 1 or 2 ICANS. And patients with grade 3 or higher ICANS are usually treated with corticosteriods in addition to supportive therapy. Patients with grade 4 or more severe ICANS usually need therapy on the intensive care unit along with intubation and mechanical ventilation [43]. In patients with depressed level of consciousness, dexamethasone should be used to control the seizure of disease [44]. Tocilizumab, the IL- 6 antagonist, is not recommended using for ICANS according to relevant studies because it has poor capacity of Blood-Brain-Barrier (BBB) penetration. Anakinra, an IL-1 receptor antagonist, have demonstrated great potential to prevent both CRS and ICANS in murine models [45]. Besides, lenzilumab, a neutralizing antibody against granulocyte-macrophage colony-stimulating factor (GMCSF), also has shown great potency to relieve the severity of neurotoxicity in a phase II study [46]. Cerebral edema is the most serious complication of ICANS. In the clinical trial (JCAR015)for patients with ALL, 5 patients died of severe cerebral edema with blood-brain barrier disruption. Mannitol or hypertonic saline should be used to decrease cranial pressure of patients with cerebral edema [47]. Magnetic Resonance Imaging (MRI) and Electroencephalogram (EEG) abnormalities are common in patients with ICANS, which can help us detect and manage neurotoxicity after CAR-T cell therapy better [48].

\section{Other adverse events}

Lymphodepletion can reduce the level of regulatory $\mathrm{T}$ cells and promote proliferation of CAR-T cells. However, lymphodepletion by fludarabine and cyclophosphamide may cause hematological abnormalities such as neutropenia, leukopenia, anemia, and thrombocytopenia. Off-target toxicity of CAR-T cell therapy is that CAR-T cells react with normal tissue without expression of targeting antigen. On-target offtumor toxicity of CAR-T cell therapy is that CAR-T cells recognize and bind to targeted antigens expressed on normal cells, and the outcomes are more severe when occurred on treatment for solid tumors than hematological malignancies. In addition, on-target ontumor toxicity is induced by rapid destruction of tumor cells. The release of contents in tumor cells can cause metabolic disorder and affect organ functions. On-target on-tumor toxicity, or tumor lysis syndrome, was reported in the CAR-T cell therapy for patients with ALL [12]. Tumor lysis syndrome of CAR-T cell therapy can result in life-threatening arrhythmias and renal failure when patients with high tumor burden. Therefore, lymphodepleting chemotherapy is important before administration of CAR-T cells in these patients. Infections are common after CAR-T cell therapy. The increased risk of infections are associated with the use of corticosteroids and tocilizumab. Monitoring and treatment of hypogammaglobulinemia, prevention and management of infections are important.

\section{Current problems of CAR-T cell therapy in B-NHL}

Although CAR-T cell therapies have had a marked impact on the management of patients with B-cell malignancies including chemotherapy refractory aggressive BNHL, initial CRs were observed in about $90 \%$ of patients with ALL in clinical trials while the CR rate of patients with B-NHL was inferior [49]. There are several reasons for the inferior responses. Lymphomas are solid tumors which have a physical barrier to prevent CAR-T cells to contact tumor cells. Besides, CAR-T cells have to overcome the immunosuppressive effects of regulatory $\mathrm{T}$ cells (Tregs), tumor-associated macrophages (TAMs), myeloid-derived suppressor cells (MDSCs) and inhibitory substances in the tumor microenvironment (TME). CAR-T cells could also lack chemokines to enter lymphoid tissues [50,51]. Tregs play a vital role in maintaining immune tolerance to self-antigens but can also suppress antitumor immunity. One study found that antibodymediated consumption of 4-1BB-expressing cells can decrease tumor growth on murine tumor models and 4-1 BB was highly selectively for human tumor Tregs [52]. The combination of CAR-T cells with corresponding antibodies may increase antitumor effects of CAR-T cell therapy. The TAMs are one of the components of nontumor stromal cells in TME and play an important role in occurrence and progression of tumors including hematological malignancies [53, 54]. Combined with agents that target TAMs and developing CARs that 
target antigens expressed by TAMs can overcome the immunosuppression. The programmed cell death protein 1 (PD-1) and programmed death-ligand 1/2 (PDL1/L2) play an important role in suppressing the antitumor immune response. The up-regulation of PD-1 is associated with T-cell exhaustion. Overexpression of PDL1 in tumor cells has been confirmed to inhibit CAR-T cell function [55]. Blocking the pathway with immune checkpoint inhibitors can reverse T-cell exhaustion and increase the antitumor effects of CAR-T cell therapy [51, 56]. Furthermore, age of patient and T-cell quality may affect the function of CAR-T cell. A clinical trial analyzed differences in production features and phenotype of CD19 CAR-T cells with CD28 co-stimulatory domains between ALL and B-NHL patients. In the clinical trial, $100 \%$ of ALL patients and $94 \%$ of B-NHL patients received CAR-T cells at the target dose of $1 \times 10^{\wedge} 6$ cells/ kg. CAR-T cells in ALL patients expanded better than that in NHL patients. Besides, the CAR-T cells from ALL patients contained more naive $T$ cells $(\mathrm{TN})$ than CAR-T cells from B-NHL patients did. They also found that CAR-T cells of younger patients $(<20$ years $)$ demonstrated an increased fold expansion compared with older patients ( $\geq 20$ years). The ORR was $84 \%(30 / 36)$ in ALL patients and 62\% (32/52) in B-NHL patients [57]. TNcells (CD45RA + CCR7+) have long-term proliferation in vivo after administration, which can possibly enhance the clinical outcome of CAR-T cell therapy [58]. Analysis of the clinical trial demonstrated no significant differences in other phenotypes between ALL group and NHL group. The inferior response rate of CAR-T cell therapy for NHL patients may attribute to lower quality of CAR-T cells manufactured from patients with NHL. Further efforts is required to overcome the limitation. Manufacture failure and high cost of the therapy impact the clinical applications of CAR-T therapy. "Off-theshelf" strategies and allogeneic CAR-T products could help us overcome these limitations [59, 60]. Besides, CAR-T cell-associated toxicities including CRS and ICANS have impeded the feasibility of CAR-T therapy and limited the number of patients who are eligible for this treatment. Although there are some solutions to deal with adverse events, new strategies which can prevent the occurrence of toxicities associated with CAR-T therapy are still needed. Modifying CAR structure could be one solution to decrease the incidence of adverse events. A phase I clinical trial found that a new antiCD19 CAR-T cell (CD19-BBz(86)) with co-stimulatory $4-1 \mathrm{BB}$ and $\mathrm{CD} 3 \zeta$ domains produced lower levels of cytokines. And no patients developed high-grade CRS or ICANS [61]. Utilizing humanized antibody fragments could decrease the immunogenicity of CAR and decrease the release of cytokines. For example, in the clinical trial of Hu19-CD828Z, designed with a scFv from a fully- human anti-CD19 monoclonal antibody and CD28 costimulatory domain, a lower incidence of high-grade ICAN $\mathrm{S}$ than murine-derived CAR was observed [24].

\section{New developments of CAR-T cell therapy}

Anti-CD19 CAR-T cell therapies have significantly improved efficacy in patients with refractory B-NHL. However, some patients relapsed after anti-CD19 CAR-T cell therapy. It is important to understand the mechanisms of relapse or non-response in patients with B-NHL after CAR-T cell therapy. There are two main mechanisms of relapse. The mechanisms of antigen positive relapse are associated with limited CAR-T cells persistence or B cell aplasia. The determinants of CAR-T cell persistence have yet to be fully determined. Internal quality of $\mathrm{T}$ cell and $\mathrm{T}$ cell phenotype could influence CAR- $\mathrm{T}$ cell persistence in vivo. And the mechanisms of antigen negative relapse are antigen down regulation and antigen loss. These limitations of current CAR-T cell therapy indicate the necessity of new-generation CAR- $T$ cell therapy (Table 4).

\section{B-cell activating factor receptor (BAFF-R)-targeted CAR-T cell therapy}

Although CAR-T cells have achieved great efficacy on Bcell malignancies, antigen loss and lack of therapeutic persistence could result in disease relapse, which indicate the need for novel target selection and for improving the efficacy and persistence of the CAR-T cells. Bcell activating factor (BAFF) is a member of the tumor necrosis factor (TNF) superfamily, and it can activate and promote proliferation of B lymphocytes [62]. BAFF$\mathrm{R}$ is a pro-survival receptor expressed on most malignant $B$ cells and plays an important role in the proliferation of malignant lymphoma cells. Although BAFF-R is widely expressed on B-cells, serum BAFF levels were elevated in B-NHL patients compared to BAFF levels in healthy donors. High BAFF levels indicated aggressive disease and poor response to therapy. The blockade of BAFF and BAFF-R can be a therapeutic strategy in BNHL [63]. The BAFF-R-targeted CAR-T cells can eliminate human malignant $B$ cells expressing BAFF-R. Besides, BAFF-R-targeted CAR-T cells can kill human lymphoma and ALL cells with CD19 antigen loss in murine models effectively [62].

\section{CD20-targeted CAR-T cell therapy}

The majority of B-cell lymphomas express CD20 and the over-expression of CD20 could indicate highly progressive disease [64]. CD20 phosphorylation was reported to be higher in proliferating malignant $B$ cells than normal B cells [65]. A phase I clinical trial studied the second generation anti-CD20 CAR-T cells in 7 patients with refractory and relapsed DLBCL. Six of seven patients could 
be evaluated after CAR-T therapy and five of whom experienced tumor regression. Four of six evaluable patients achieved PR. However, three of these four patients eventually relapsed [66].

\section{CD19/CD20-targeted CAR-T cell therapy}

There was a phase II clinical trial of co-administration of anti-CD19 CAR-T cells and anti-CD20 CAR-T cells for patients with refractory and relaped DLBCL. Twenty-five patients were enrolled in this trial and 21 patients received CAR-T infusion. Seventeen patients reached OR with 11 patients in CR. And the toxicities were manageable [67]. The result indicated an accessible choice for patients with refractory or relapsed DLBCL. A phase I/ IIa clinical trial was designed to evaluate the efficacy and safety of TanCAR7 $\mathrm{T}$ cells for patients with relapsed or refractory B-cell lymphoma. TanCAR7 $\mathrm{T}$ cells can target both CD19 and CD20 with co-stimulatory domain of 41BB. A total of 28 patients received the infusion of TanCAR7 cells. The first 7 patients were treated at a dose of $0.5-6 \times 10^{\wedge} 6 \mathrm{cells} / \mathrm{kg}$, and 21 patients were treated at a dose of $1-8 \times 10^{\wedge} 6$ cells $/ \mathrm{kg}$. The ORR was $79 \%$ and the CR rate was $71 \%$. PFS rate was $64 \%$ at 12 months followup. CRS occurred in $50 \%$ of patients (14/28). Grade 3 or higher CRS were observed in $14 \%$ of patients. ICANS occurred in 6 patients. And no patients developed grade 3 or higher ICANS [68].

\section{CD22-targeted CAR-T cell therapy}

CD22, a member of sialic acid-binding immunoglobulinlike lectin (Siglec) family, is an inhibitory co-receptor of $\mathrm{B}$-cell receptor that is exclusively expressed on B-cells. CD22 is highly expressed on B-cell lymphomas and leukemias so it has become an therapeutic target of cell therapy [69]. A phase I dose escalation study evaluated the efficacy and safety of CD22-targeted CAR-T cell therapy in patients with large B-cell lymphoma who relapsed following anti-CD19 CAR-T therapy. Three patients whose disease progressed after multiple treatments including previous anti-CD19 CAR-T therapy were enrolled. All patients received $C R$ and no severe adverse events occurred after infusion of CD22 CAR-T cells. The study showed that CD22 could serve as a potential target of CAR-T cell therapy in large B-cell lymphoma [70].

\section{CD19/CD22 dual-targeted CAR-T cell therapy}

Clinical trials of CD19/CD22 bispecific CAR-T cell therapy have manifested encouraging efficacy in B-cell malignancies. One patient with B-cell acute lymphoblastic leukemia (B-ALL) has maintained minimal residual disease (MRD)-negative remission for over 14 months after CD19/CD22 bispecific CAR-T cell therapy [71]. Besides, there is an ongoing phase I/II research studies the efficacy and safety of AUTO3, a bispecific CAR-T targeting both CD19 and CD22, in patients with relapsed/refractory DLBCL. Twenty-three patients were recruited and 16 patients received AUTO3. Sixty-nine percent of patients received OR and $56 \%$ of patients reached CR among 16 patients with DLBCL. There was no high grade adverse events related to AUTO3 treatment. Besides, there was another clinical trial that aimed at the efficacy and adverse events of CD19/CD22 CAR-T cell therapy for aggressive B-cell lymphoma involving gastrointestinal tract. Ten patients got OR and 7 patients achieved CR among all 14 recruited individuals with Bcell lymphoma involving gastrointestinal tract. CRS and gastrointestinal tract adverse events were manageable [72]. However, anti-CD22 agents cannot differentiate normal B cells from malignant B cells, resulting in side

Table 4 B cell lymphoma antigens targeted by CAR-T cells

\begin{tabular}{|c|c|c|}
\hline $\begin{array}{l}\text { CAR-T } \\
\text { antigen }\end{array}$ & Clinical study & Disease \\
\hline CD19 & $\begin{array}{l}\text { Safety and feasibility of anti-CD19 CAR T cells with fully human binding domains in patients with B-cell } \\
\text { lymphoma }\end{array}$ & $\begin{array}{l}\text { B-cell lymphoma; } \\
\text { B-ALL }\end{array}$ \\
\hline BAFF-R & Antitumor efficacy of BAFF-R targeting CAR T cells manufactured under clinic-ready conditions & $\begin{array}{l}\mathrm{B}-\mathrm{ALL} ; \\
\mathrm{B}-\mathrm{NHL}\end{array}$ \\
\hline CD20 & $\begin{array}{l}\text { Phase II trial of co-administration of CD19- and CD20-targeted chimeric antigen receptor T cells for relapsed } \\
\text { and refractory diffuse large B cell lymphoma }\end{array}$ & R/R DLBCL \\
\hline CD22 & CD19/CD22 Dual-Targeted CAR-T Therapy Active in Relapsed/Refractory DLBCL & R/R DLBCL \\
\hline CD79b & Targeting CD79b for Chimeric Antigen Receptor T-Cell Therapy of B-Cell Lymphomas & B-cell lymphoma \\
\hline CD37 & Preclinical development of CD37CAR T-cell therapy for treatment of B-cell lymphoma & $\mathrm{R} / \mathrm{R}$ B-NHL \\
\hline PD-1 & $\begin{array}{l}\text { CD19-Specific CAR-T Cells that Express a PD-1/CD28 Chimeric Switch-Receptor is Effective in Patients with } \\
\text { PD-L1 Positive B-Cell Lymphoma }\end{array}$ & $\begin{array}{l}\text { PD-L1 Positive B-Cell } \\
\text { Lymphoma }\end{array}$ \\
\hline $\lg K$ & $\begin{array}{l}\text { T lymphocytes redirected against the } \mathrm{k} \text { light chain of human immunoglobulin efficiently kill mature B } \\
\text { lymphocyte-derived malignant cells }\end{array}$ & $\begin{array}{l}\text { Low-grade NHL; } \\
\text { B-CLL }\end{array}$ \\
\hline
\end{tabular}

Abbreviations: $C A R$ chimeric antigen receptor, $B$ - $A L L$ B-cell acute lymphoblastic leukemia, $B$-NHL B-cell non-Hodgkin lymphoma, $R / R$ DLBCL relapsed and refractory diffuse large $B$ cell lymphoma, $P D-1$ programmed cell death protein-1, $P D$ - $L 1$ programmed death ligand $1, B$ - $C L L B$-cell chronic lymphocytic leukemia 
effects such as hemocytopenia. More strategies need to be developed to overcome the limitation of CD22targeted CAR-T cell therapy.

\section{Trispecific CD19-CD20-CD22-targeted duoCAR-T}

A preclinical research engineered trispecific duoCAR-T cells that target CD19, CD20, and CD22. The duoCAR consisted of a CAR that can target CD19 and CD20, linked by the P2A self-cleaving peptide to a second CAR targeting CD22. In the murine models bearing a mixture of B-cell lymphoma lines composed of CD19 negative, CD20 negative, and CD22 negative variants, the trispecific duoCAR-T cells could efficiently kill tumor cells. In contrast, monoCAR-T cells such as CD19-targeted CAR-T cells failed to prevent tumor progression. The research demonstrated that multispecific CAR-T cells can be a promising method to prevent antigen down regulation or antigen loss relapse [73].

\section{CD79b-targeted CAR-T cell therapy}

$\mathrm{B}$-cell receptor (BCR) is important for persistence and development of mature B cells and plays an essential role on tumorigenesis of B-cell lymphoma. CD79b, a signaling part of $\mathrm{B}$-cell receptor, is a B-cell-restricted surface antigen expressed on both mature $\mathrm{B}$ cells and Bcell-derived malignancies such as B-NHL. One study detected the expression of $\mathrm{CD} 79 \mathrm{~b}$ on patients with different types of B-cell malignancies including DLBCL, Burkitt lymphoma, FL, and evaluated the efficacy of anti-CD79b CAR-T cells in vitro and in vivo. They found that the expression of CD79b on tumor cells of patients with different types of B-cell malignancies was wide. The CD79b mean fluorescence intensities (MFIs) of malignant lymphoma cells were similar to or higher than the MFI of normal B cells. Anti-CD79b CAR-T cells showed remarkable efficacy on tumors cells [74].

\section{CD37-targeted CAR-T cell therapy}

CD37 is a member of tetraspanin superfamily mainly expressed on mature $\mathrm{B}$ cells including normal and malignancy B cells. The expression of CD37 in normal tissues is restricted to lymphoid organs such as spleen, lymph nodes and bone marrow [75]. High expression of CD37 has been detected across multiple types of BNHL, which makes CD37 a potential target of immunotherapy for B-NHL patients [76]. The function of CD37 is not fully understood, but researches indicated that CD37 was involved in immune regulation and tumor supression [77]. CD37 is one of the potential targets for immunotherapy of B-NHL and some studies are ongoing, for example, 212Pb-NNV003, IMGN529, AGS67E, BI 836826 and anti-CD37 CAR-T. A preclinical study confirmed the high expression of CD37 on tumor cells of DLBCL, FL, MCL, MZL and CLL, which demonstrated the remarkable efficacy of anti-CD37 CAR-T to both CD19 positive B-cell lymphoma cell line and CD19 negative cell line in vitro. Besides, the CAR-T product reduced the growth of tumor cells in murine models and prolonged survival of mice, regardless of CD19 expression [76].

\section{PD-1 and CAR-T}

PD-1 and PD-L1/L2 have been proved the important role on tumor immune escape, tumor progression and tumor survivals in various malignancies. And many experiments showed the highly expressed PD-L1 on lymphoma cells and up-regulated level of PD-1 in tumor-infiltrating lymphocytes, which indicates that PD-1/PD-L1 could be a therapeutic target for lymphoma. PD-1 is mainly expressed on activated $\mathrm{T}$ cells, $\mathrm{B}$ cells, and natural killer cells. PD-L1 or PD-L2 are mainly expressed on varieties of immune cells and tumor cells. High frequency of PD-L1 positivity has been detected in many types of B-cell lymphomas. The expression of PD-L1 was detected in 80 of 260 patients with DLBCL in one study [78]. There was a multicenter study of anti-CD19 CAR-T cells expressing PD-1/CD28 chimeric switch-receptor in 17 patients with large B-cell lymphoma including 15 PD-L1+ cases. Ten patients received OR and 7 of them received $C R$, while no severe ICANS or CRS occurred. This study showed the encouraging efficacy and safety of the anti-CD19 CAR-T cells expressing PD-1/CD28 chimeric switch-receptor. Besides, combination of CAR-T cell therapy and PD-1 blockade such as nivolumab and pembrolizumab have been applied to enhance anti-tumor efficacy in murine models and clinical trials. Eleven patients with relapsed/refractory lymphoma received CAR-T cells infusion at a dose of 5$11 \times 10^{\wedge} 6$ cells $/ \mathrm{kg}$. All 11 patients were infused with nivolumab at a dose of $3 \mathrm{mg} / \mathrm{kg}$ after 3 days of CD19 CAR-T cells infusion. Nine patients $(81.8 \%)$ achieved OR with 5 patients (45.5\%) in CR. CRS occurred in 9 patients and all CRS were grade 1 or 2 . Besides, no patients developed ICANS in the study. Other adverse events such as cytopenia and febrile syndrome were manageable [79, 80]. Furthermore, PD-1 not only can enhance the anti-tumor effect of CAR-T, but also can avoid B-cell aplasia via killer inhibitory receptor (KIR)/PD-1-based inhibitory antiCD19 CAR-T. When KIR is engaged to human leukocyte antigen C1 (HLA-C1) on normal B-cells, it will deliver an inhibitory signaling via the intracellular PD-1 domain to avoid the destruction of normal B-cells caused by CAR-T cells (Fig. 3) [81].

\section{Multi-antigen-targeted CAR-T}

Relevant studies have shown that antigen escape and ontarget, off-tumor toxicities of CAR-T limit the application greatly [82]. Multi-antigen-targeted CAR-T, a new developing direction of CAR-T, is potential in 
overcoming antigen escape and on-target, off-tumor toxicities of previous CAR-T therapies. Multi-antigentargeted CAR-T therapies mainly include pooled CAR-T cells, dual CAR-T cells, tandem CAR-T cells and trivalent CAR-T cells. Pooled CAR-T cells are a mixture of two CAR-T cell lines that target different antigens. Dual CAR- $\mathrm{T}$ is that two different chimeric antigen receptors are expressed in a single engineered $\mathrm{T}$-cell. Tandem CAR-T is that two antigen-binding domains are connected in tandem to a single CAR. And trivalent CAR-T is that three distinct CARs are expressed in a single $T$ cell. Multi-antigen-targeted CAR-T using the "OR" logic gate can effectively mitigate antigen escape and enhance anti-tumor efficacy while the "AND" and "NOT" logicgated CAR- $T$ cells can modulate the relationship between anti-tumor effect and on-target, off-tumor toxicities [83].

\section{Armored CAR-T cells and fourth-generation CAR-T}

The armored CAR-T cell consists of two co-stimulatory domains, for example, CD28/4-1BB/CD3 $\zeta$ or CD28/OX$40 / C D 3 \zeta$, while second-generation CAR-T cell, the most widely used CAR-T in clinical trials, consists of one costimulatory domain. In comparison to conventional CAR-T, the armored CAR-T cells can achieve stronger levels of proliferation, persistence and IL-2 production. The armored CAR-T cells have superior activity and persistence in murine lymphoma models. However, they have not been widely applied in clinical trials of human [84, 85]. Fourth-generation CAR-T is called $\mathrm{T}$ cell redirected for antigen-unrestricted cytokine-initiated killing (TRUCKs), which can produce and release transduced cytokines such as IL-12, IL-15 or IL-18 to enhance the activity of CAR-T cells, change the tumor environment and achieve self-activation by autocrine pathways [86, 87].

\section{Allogeneic CAR-T cell therapy and universal CARs}

Autologous CAR-T therapies have achieved great clinical progress in B-NHL. However, some patients may fail to receive CAR-T cells infusion as a result of manufacturing failures or disease progression during the manufacturing process. Besides, many patients cannot afford the high cost of the therapy. These limitations impact the clinical applications of autologous CAR-T therapy [88]. Allogeneic CAR-T cell therapy uses T-cells collected from healthy donors, which could overcome the disfunction of T-cells from patients. And the cost of CAR-T therapy can be decreased due to the industrial production of donor-drived T-cells. However, there are still some problems exist in allogeneic CAR-T cell therapy. One of the predominant problems are the risk of graftversus-host disease (GVHD). Besides, the allogeneic Tcells could be eliminated by the immune systems of recipients, which could impact the antitumor efficacy of CAR-T cells. Eliminating the expression of T-cell receptor (TCR) and CD52 by gene editing technologies or other feasible approaches, for example, adding a suicide gene such as inducible caspase 9 (iC9) to the allogeneic CAR-T cells, could manage these adverse effects [60, 89]. Besides, the conventional design of chimeric antigen receptor and manufacturing process of CAR-T cells lead to the expensive cost of this therapy, which limits the clinical uses too. New chimeric antigen receptors can be designed with a modular method. The antigen recognition domain of CAR-T cell is separated from the signaling domain of CAR-T cell so that the antigen can be changed without the need for redesigning the CAR-T cells. This new CAR can serve as a universal CAR (UniCAR). The UniCAR-T cells remain inactive until bispecific switch molecules correlate the CAR- $T$ cells with tumor cells expressing targeting antigens, and the degree of response can be regulated by adjusting the concentration of these molecules to balance the efficacy and adverse effects of CAR-T cell therapy [90].

\section{Conclusion}

In summary, for those patients with relapsed or refractory B-NHL who had unsatisfactory prognosis treated by chemotherapeutic regimens and other new therapeutic agents, CAR-T cell therapy, especially anti-CD19 CAR-T cell therapy, has demonstrated great efficacy in plenty of clinical or preclinical trials. And four CAR-T cell products have been approved by FDA and/or EMA. Outcomes in adults with B-NHL are variable with $\mathrm{CR}$ rates ranging from 52 to $82 \%$. The construct of CAR-T product, bridging therapy, inflammation and tumor burden can affect the outcomes of this therapy. However, there exist some problems in spite of the great efficacy. CRS, ICANS and other adverse events such as neutropenia and off-target toxicity were observed. The occurrence rates of CRS range from 42 to $93 \%$ and the rates of grade 3 or higher CRS range from 2 to $22 \%$. Low-grade adverse events are manageable while severe side effects should be treated by tocilizumab, corticosteriods, vasoactive drugs, mechanical ventilation and other supportive measures. Hemofiltration and plasma exchange can be alternative therapeutic methods for severe CRS. Besides, the outcomes of patients with B-NHL treated by CAR-T cell therapy were inferior to patients with ALL. Physical barrier of B-NHL, tumor microenvironment and inherent quality of $\mathrm{T}$ cells may explain the inferior response rate. Furthermore, parts of patients relapsed after anti-CD19 CAR-T cell therapy, which were due to limited of CAR-T cells persistence, CD19 antigen loss or antigen down-regulation of tumor cells. To overcome the limitation of anti-CD19 CAR-T, developments of new generation of the therapy are ongoing. For example, 
A. On-target off-tumor

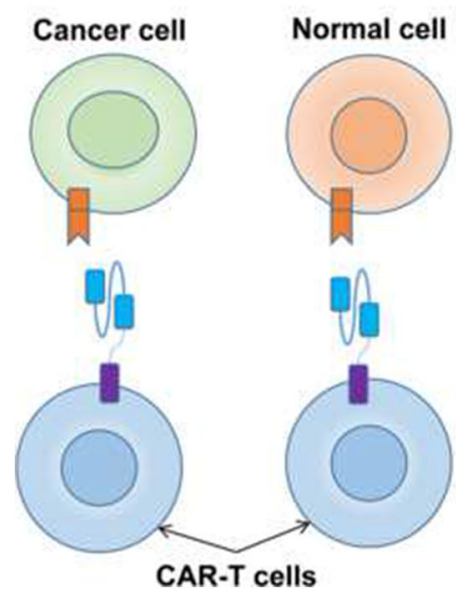

B. Mechanism of KIR / PD-1

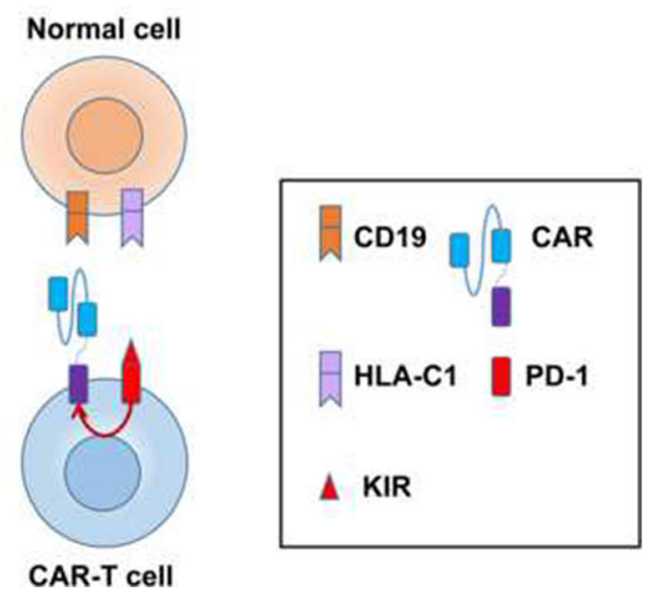

Fig. 3 The mechanism of on-target off-tumor and killer inhibitory receptor (KIR) / PD-1-based inhibitory anti-CD19 CAR-T. a CAR-T cells can recognize and bind to targeted antigens (CD19) expressed on normal cells and cause on-target off-tumor toxicity; $\mathbf{b}$ The activation of CAR-T cells can be inhibited by PD-1 signal when KIR on CAR-T cells are engaged to HLA-C1 on normal cells, which can avoid the destruction of normal cells and on-target off-tumor toxicity of CAR-T cell therapy

CD20-targeted CAR-T, CD19/CD22 dual-targeted CART, CD79b-targeted CAR-T, CD37-targeted CAR-T and CAR-T expressing PD-1/CD28 chimeric switch-receptor have demonstrated encouraging effects. Thirdgeneration CAR-T and armored CAR-T can achieve stronger levels of proliferation, persistence and IL-2 production than previous CAR-T cell in vitro or vivo. Besides, the allogeneic CAR-T cell therapy could make the therapy available to more patients. Furthermore, researchers should try their best to improve the safety and efficacy of CAR-T to make patients benefit from this powerful weapon against B-cell malignancies.

\section{Abbreviations}

CAR-T : Chimeric antigen receptor T-cell; B-NHL: B-cell non-Hodgkin lymphoma; ScFv: Single chain variable fragments; FDA: The United States Food and Drug Administration; EMA: European Medicines Agency; MCL: Mantle cell Iymphoma; OR: Objective response; CR: Complete response; ORR: Objective response rate; PFS: Progression-free survival; DLBCL: Diffuse large B-cell lymphoma; FL: Follicular lymphoma; ASCT: Autologous hematopoietic stemcell transplantation; CRS: Cytokine release syndrome; ICANS: Immune effector cell-associated neurotoxicity syndrome; CRP: C-reactive protein; TNFa: Tumor necrosis factor alpha; IFNY: Interferon gamma; GM-CSF: Granulocytemacrophage Colony Stimulating Factor; ANP: Atrial natriuretic peptide; JAKSTAT: Janus kinase-signal transducers and activators of transcription; BAFFR: B-cell activating factor receptor; Siglec: Sialic acid-binding immunoglobulin-like lectin; PD-1: Programmed cell death protein-1; PD-L1/ L2: Programmed cell death protein ligand 1/2; HLA : Human leukocyte antigen; KIR: Killer inhibitory receptors; TRUCKs: T cell redirected for antigenunrestricted cytokine-initiated killing; GVHD: Graft-versus-host disease; iC9: Inducible caspase 9; Tregs: Regulatory T cells; TME: Tumor microenvironment; TAMs: Tumor-associated macrophages; MDSCs: Myeloidderived suppressor cells; TN: Naive T cells; TCM: Central memory T cells; TEM: Effector memory T cells; PFS: Progression-free survival; ALL: Acute lymphoblastic leukemia

Acknowledgments

Not applicable.

\section{Authors' contributions}

Zixun Yin wrote the initial manuscript. Xin Wang and Ya Zhang revised the manuscript. All authors read and approved the final manuscript.

\section{Funding}

This study was funded by National Natural Science Foundation (No.82000195, No.82070203, No.81770210, No.81473486 and No.81270598); Key Research and Development Program of Shandong Province (No.2018CXGC1213); Technology Development Projects of Shandong Province (No.2017GSF18189); Translational Research Grant of NCRCH (No.2021WWB02, No.2020ZKMB01); Shandong Provincial Natural Science Foundation (No.ZR2020QH094); Taishan Scholars Program of Shandong Province; Shandong Provincial Engineering Research Center of Lymphoma; Academic Promotion Programme of Shandong First Medical University (No. 2019QL018; No.2020RC007); Technology Development Project of Jinan City (No.202019182); Shandong Provincial Hospital Youth Talent Plan; Shandong Provincial Hospital Research Incubation Fund.

\section{Availability of data and materials}

Not applicable.

\section{Declarations}

Ethics approval and consent to participate

Not applicable.

\section{Consent for publication}

Not applicable.

\section{Competing interests}

The authors declare that they have no competing interests.

\section{Author details}

'Department of Hematology, Shandong Provincial Hospital, Cheeloo College of Medicine, Shandong University, Jinan 250021, Shandong, China. ${ }^{2}$ School of Medicine, Shandong University, Jinan 250021, Shandong, China. ${ }^{3}$ Department of Hematology, Shandong Provincial Hospital Affiliated to Shandong First Medical University, Jinan 250012, Shandong, China. ${ }^{4}$ Shandong Provincial Engineering Research Center of Lymphoma, Jinan 250021, Shandong, China. ${ }^{5}$ Branch of National Clinical Research Center for Hematologic Diseases, Jinan 250021, Shandong, China. ${ }^{6}$ National Clinical Research Center for Hematologic Diseases, the First Affiliated Hospital of Soochow University, Suzhou 251006, China. 
Received: 16 April 2021 Accepted: 11 June 2021

Published online: 13 July 2021

\section{References}

1. Yang $H$, Green MR. Epigenetic programing of B-cell lymphoma by BCL6 and its genetic deregulation. Front Cell Dev Biol. 2019;7. https://doi.org/10.3389/ fcell.2019.00272.

2. Roschewski M, Staudt LM, Wilson WH. Diffuse large B-cell lymphomatreatment approaches in the molecular era. Nat Rev Clin Oncol. 2014;11(1): 12-23. https://doi.org/10.1038/nrclinonc.2013.197.

3. Linschoten M, Kamphuis J, van Rhenen A, Bosman L, Cramer M, Doevendans $\mathrm{P}$, et al. Cardiovascular adverse events in patients with nonHodgkin lymphoma treated with first-line cyclophosphamide, doxorubicin, vincristine, and prednisone (CHOP) or CHOP with rituximab (R-CHOP): a systematic review and meta-analysis. Lancet Haematol. 2020;7(4):e295-308. https://doi.org/10.1016/S2352-3026(20)30031-4.

4. Mondello P, Mian M. Frontline treatment of diffuse large B-cell lymphoma: beyond R-CHOP. Hematol Oncol. 2019;37(4):333-44. https://doi.org/10.1002/ hon.2613.

5. Brudno JN, Kochenderfer JN. Chimeric antigen receptor T-cell therapies for lymphoma. Nat Rev Clin Oncol. 2018;15(1):31-46. https://doi.org/10.1038/ nrclinonc.2017.128.

6. van Dorsten R, Lambson B, Wibmer C, Weinberg M, Moore P, Morris L. Neutralization Breadth and Potency of Single-Chain Variable Fragments Derived from Broadly Neutralizing Antibodies Targeting Multiple Epitopes on the HIV-1 Envelope. J Virol. 2020:94(2):e01533-19.

7. Johnson P, Abramson J. Patient selection for chimeric antigen receptor (CAR) T-cell therapy for aggressive B-cell non-Hodgkin lymphomas. Leuk Lymphoma. 2020;61(11):2561-7. https://doi.org/10.1080/10428194.2020.1 786563.

8. Bachanova V, Perales M, Abramson J. Modern management of relapsed and refractory aggressive B-cell lymphoma: a perspective on the current treatment landscape and patient selection for CAR T-cell therapy. Blood Rev. 2020;40:100640. https://doi.org/10.1016/j.blre.2019.100640.

9. Schuster SJ, Svoboda J, Chong EA, Nasta SD, Mato AR, Anak O, et al. Chimeric antigen receptor T cells in refractory B-cell lymphomas. N Engl J Med. 2017:377(26):2545-54. https://doi.org/10.1056/NEJMoa1708566.

10. Gofshteyn JS, Shaw PA, Teachey DT, Grupp SA, Maude S, Banwell B, et al. Neurotoxicity after CTL019 in a pediatric and young adult cohort. Ann Neurol. 2018;84(4):537-46. https://doi.org/10.1002/ana.25315.

11. Lee DW, Kochenderfer JN, Stetler-Stevenson M, Cui YK, Delbrook C, Feldman SA, et al. T cells expressing CD19 chimeric antigen receptors for acute lymphoblastic leukaemia in children and young adults: a phase 1 doseescalation trial. Lancet. 2015;385(9967):517-28. https://doi.org/10.1016/S014 0-6736(14)61403-3

12. Maude SL, Frey N, Shaw PA, Aplenc R, Barrett DM, Bunin NJ, et al. Chimeric antigen receptor $T$ cells for sustained remissions in leukemia. N Engl J Med. 2014;371(16):1507-17. https://doi.org/10.1056/NEJMoa1407222.

13. Danylesko I, Chowers G, Shouval R, Besser M, Jacoby E, Shimoni A, et al. Treatment with anti CD19 chimeric antigen receptor T cells after antibodybased immunotherapy in adults with acute lymphoblastic leukemia. Curr Res Transl Med. 2020;68(1):17-22. https://doi.org/10.1016/j.retram.2019.12. 001.

14. Klener P. Advances in Molecular Biology and Targeted Therapy of Mantle Cell Lymphoma. Int J Mol Sci. 2019;20(18):4417.

15. Gerson JN, Barta SK. Mantle cell lymphoma: which patients should we transplant? Curr Hematol Malig Rep. 2019;14(4):239-46. https://doi.org/10.1 007/s11899-019-00520-0

16. Arora PC, Portell CA. Novel therapies for relapsed/refractory mantle cell lymphoma. Best Pract Res Clin Haematol. 2018;31(1):105-13. https://doi. org/10.1016/j.beha.2017.10.010.

17. Wang M, Munoz J, Goy A, Locke FL, Jacobson CA, Hill BT, et al. KTE-X19 CAR T-cell therapy in relapsed or refractory mantle-cell lymphoma. N Engl J Med. 2020:382(14):1331-42. https://doi.org/10.1056/NEJMoa1914347.

18. Lossos IS. Molecular pathogenesis of diffuse large B-cell lymphoma. J Clin Oncol. 2005;23(26):6351-7. https://doi.org/10.1200/JCO.2005.05.012.

19. Locke FL, Neelapu SS, Bartlett NL, Siddiqi T, Chavez JC, Hosing CM, et al. Phase 1 results of ZUMA-1: a multicenter study of KTE-C19 anti-CD19 CAR T cell therapy in refractory aggressive lymphoma. Mol Ther. 2017:25(1):285-95. https://doi.org/10.1016/j.ymthe.2016.10.020.
20. Neelapu S, Locke F, Bartlett N, Lekakis L, Miklos D, Jacobson C, et al. Axicabtagene Ciloleucel CAR T-cell therapy in refractory large B-cell lymphoma. N Engl J Med. 2017;377(26):2531-44. https://doi.org/10.1056/ NEJMoa1707447.

21. Locke FL, Ghobadi A, Jacobson CA, Miklos DB, Lekakis LJ, Oluwole OO, et al. Long-term safety and activity of axicabtagene ciloleucel in refractory large B-cell lymphoma (ZUMA-1): a single-arm, multicentre, phase 1-2 trial. Lancet Oncol. 2019;20(1):31-42. https://doi.org/10.1016/S1470-2045(18)3 0864-7.

22. Kochenderfer JN, Somerville RPT, Lu T, Shi V, Bot A, Rossi J, et al. Lymphoma remissions caused by anti-CD19 chimeric antigen receptor T cells are associated with high serum Interleukin-15 levels. J Clin Oncol. 2017;35(16): 1803-13. https://doi.org/10.1200/JCO.2016.71.3024.

23. Alabanza L, Pegues M, Geldres C, Shi V, Wiltzius JJW, Sievers SA, et al. Function of novel anti-CD19 chimeric antigen receptors with human variable regions is affected by hinge and transmembrane domains. Mol Ther. 2017:25(11):2452-65. https://doi.org/10.1016/j.ymthe.2017.07.013.

24. Brudno JN, Lam N, Vanasse D, Shen Y-W, Rose JJ, Rossi J, et al. Safety and feasibility of anti-CD19 CAR T cells with fully human binding domains in patients with B-cell lymphoma. Nat Med. 2020;26(2):270-80. https://doi. org/10.1038/s41591-019-0737-3.

25. Schuster SJ, Bishop MR, Tam CS, Waller EK, Borchmann P, McGuirk JP, et al. Tisagenlecleucel in adult relapsed or refractory diffuse large B-cell lymphoma. N Engl J Med. 2019;380(1):45-56. https://doi.org/10.1056/ NEJMoa1804980.

26. Abramson J, Palomba M, Gordon L, Lunning M, Wang M, Arnason J, et al. Lisocabtagene maraleucel for patients with relapsed or refractory large Bcell lymphomas (TRANSCEND NHL 001): a multicentre seamless design study. Lancet (London, England). 2020;396(10254):839-52.

27. Pinnix C, Gunther J, Dabaja B, Strati P, Fang P, Hawkins M, et al. Bridging therapy prior to axicabtagene ciloleucel for relapsed/refractory large B-cell lymphoma. Blood Adv. 2020;4(13):2871-83. https://doi.org/10.1182/blooda dvances.2020001837.

28. Locke FL, Rossi JM, Neelapu SS, Jacobson CA, Miklos DB, Ghobadi A, et al. Tumor burden, inflammation, and product attributes determine outcomes of axicabtagene ciloleucel in large B-cell lymphoma. Blood Adv. 2020;4(19): 4898-911. https://doi.org/10.1182/bloodadvances.2020002394.

29. Cao J-X, Wang H, Gao W-J, You J, Wu L-H, Wang Z-X. The incidence of cytokine release syndrome and neurotoxicity of CD19 chimeric antigen receptor-T cell therapy in the patient with acute lymphoblastic leukemia and lymphoma. Cytotherapy. 2020;22(4):214-26. https://doi.org/10.1016/j. jcyt.2020.01.015

30. Neelapu SS, Tummala S, Kebriaei P, Wierda W, Gutierrez C, Locke FL, et al. Chimeric antigen receptor T-cell therapy — assessment and management of toxicities. Nat Rev Clin Oncol. 2017;15(1):47-62. https://doi.org/10.1038/ nrclinonc.2017.148.

31. Liu D, Zhao J. Cytokine release syndrome: grading, modeling, and new therapy. J Hematol Oncol. 2018;11(1):121. https://doi.org/10.1186/s13045-01 8-0653-x.

32. Wang Z, Han W. Biomarkers of cytokine release syndrome and neurotoxicity related to CAR-T cell therapy. Biomark Res. 2018;6(1):4. https://doi.org/10.11 86/s40364-018-0116-0.

33. Sievers S, Watson G, Johncy S, Adkins S. Recognizing and grading CAR T-cell toxicities: an advanced practitioner perspective. Front Oncol. 2020;10:885. https://doi.org/10.3389/fonc.2020.00885.

34. Chen $H$, Wang F, Zhang $P$, Zhang $Y$, Chen $Y$, Fan $X$, et al. Management of cytokine release syndrome related to CAR-T cell therapy. Front Med. 2019; 13(5):610-7. https://doi.org/10.1007/s11684-019-0714-8.

35. Kotch C, Barrett D, Teachey DT. Tocilizumab for the treatment of chimeric antigen receptor $T$ cell-induced cytokine release syndrome. Expert Rev Clin Immunol. 2019;15(8):813-22. https://doi.org/10.1080/1744666X.2019.1629904.

36. Le RQ, Li L, Yuan W, Shord SS, Nie L, Habtemariam BA, et al. FDA approval summary: tocilizumab for treatment of chimeric antigen receptor $T$ cellinduced severe or life-threatening cytokine release syndrome. Oncologist. 2018;23(8):943-7. https://doi.org/10.1634/theoncologist.2018-0028.

37. Huarte $E_{1}$ O'Conner RS, Peel MT, Nunez-Cruz S, Leferovich J, Juvekar A, et al. Itacitinib (INCB039110), a JAK1 inhibitor, Reduces Cytokines Associated with Cytokine Release Syndrome Induced by CAR T-Cell Therapy. Clin Cancer Res. 2020;26(23):6299-309.

38. Norelli M, Camisa B, Barbiera G, Falcone L, Purevdorj A, Genua M, et al. Monocyte-derived IL-1 and IL-6 are differentially required for cytokine- 
release syndrome and neurotoxicity due to CAR T cells. Nat Med. 2018;24(6): 739-48. https://doi.org/10.1038/s41591-018-0036-4.

39. Hao Z, Li R, Meng L, Han Z, Hong Z. Macrophage, the potential key mediator in CAR-T related CRS. Exp Hematol Oncol. 2020;9(1):15. https://doi. org/10.1186/s40164-020-00171-5.

40. Karschnia P, Jordan J, Forst D, Arrillaga-Romany I, Batchelor T, Baehring J, et al. Clinical presentation, management, and biomarkers of neurotoxicity after adoptive immunotherapy with CAR T cells. Blood. 2019;133(20):221221. https://doi.org/10.1182/blood-2018-12-893396.

41. Du M, Hari P, Hu Y, Mei H. Biomarkers in individualized management of chimeric antigen receptor T cell therapy. Biomark Res. 2020;8(1):13. https:// doi.org/10.1186/s40364-020-00190-8.

42. Rubin D, Danish H, Ali A, Li K, LaRose S, Monk A, et al. Neurological toxicities associated with chimeric antigen receptor T-cell therapy. Brain J Neurol. 2019;142(5):1334-48. https://doi.org/10.1093/brain/awz053.

43. Neelapu S. Managing the toxicities of CAR T-cell therapy. Hematol Oncol. 2019;37(S1):48-52. https://doi.org/10.1002/hon.2595.

44. Azoulay E, Darmon M, Valade S. Acute life-threatening toxicity from CAR Tcell therapy. Intensive Care Med. 2020;46(9):1723-6. https://doi.org/10.1007/ s00134-020-06193-1.

45. Strati P, Ahmed S, Kebriaei P, Nastoupil L, Claussen C, Watson G, et al. Clinical efficacy of anakinra to mitigate CAR T-cell therapy-associated toxicity in large B-cell lymphoma. Blood Adv. 2020;4(13):3123-7. https://doi. org/10.1182/bloodadvances.2020002328.

46. Sterner R, Sakemura R, Cox M, Yang N, Khadka R, Forsman C, et al. GM-CSF inhibition reduces cytokine release syndrome and neuroinflammation but enhances CAR-T cell function in xenografts. Blood. 2019;133(7):697-709. https://doi.org/10.1182/blood-2018-10-881722.

47. Rice J, Nagle S, Randall J, Hinson H. Chimeric antigen receptor T cell-related neurotoxicity: mechanisms, clinical presentation, and approach to treatment. Curr Treat Options Neurol. 2019;21(8):40. https://doi.org/10.1007/ s11940-019-0580-3.

48. Strati P, Nastoupil L, Westin J, Fayad L, Ahmed S, Fowler N, et al. Clinical and radiologic correlates of neurotoxicity after axicabtagene ciloleucel in large B-cell lymphoma. Blood Adv. 2020;4(16):3943-51. https://doi.org/10.1182/ bloodadvances.2020002228.

49. Mohty M, Gautier J, Malard F, Aljurf M, Bazarbachi A, Chabannon C, et al. CD19 chimeric antigen receptor-T cells in B-cell leukemia and lymphoma: current status and perspectives. Leukemia. 2019;33(12):2767-78. https://doi. org/10.1038/s41375-019-0615-5.

50. Enblad G, Karlsson H, Loskog A. CAR T-cell therapy: the role of physical barriers and immunosuppression in lymphoma. Hum Gene Ther. 2015;26(8): 498-505. https://doi.org/10.1089/hum.2015.054.

51. Rodriguez-Garcia A, Palazon A, Noguera-Ortega E, Powell D, Guedan S. CAR-T cells hit the tumor microenvironment: strategies to overcome tumor escape. Front Immunol. 2020;11:1109. https://doi.org/10.3389/fimmu.2020.01109.

52. Freeman Z, Nirschl T, Hovelson D, Johnston R, Engelhardt J, Selby M, et al. A conserved intratumoral regulatory $T$ cell signature identifies 4-1BB as a pan-cancer target. J Clin Invest. 2020;130(3):1405-16. https://doi.org/10.1172/JCl128672.

53. Ge Z, Ding S. The crosstalk between tumor-associated macrophages (TAMs) and tumor cells and the corresponding targeted therapy. Front Oncol. 2020; 10:590941. https://doi.org/10.3389/fonc.2020.590941.

54. Komohara Y, Niino D, Ohnishi K, Ohshima K, Takeya M. Role of tumorassociated macrophages in hematological malignancies. Pathol Int. 2015; 65(4):170-6. https://doi.org/10.1111/pin.12259.

55. Qin L, Zhao R, Chen D, Wei X, Wu Q, Long Y, et al. Chimeric antigen receptor T cells targeting PD-L1 suppress tumor growth. Biomark Res. 2020; 8(1):19. https://doi.org/10.1186/s40364-020-00198-0.

56. Boussiotis V. Molecular and biochemical aspects of the PD-1 checkpoint pathway. N Engl J Med. 2016;375(18):1767-78. https://doi.org/10.1056/ NEJMra1514296.

57. Itzhaki O, Jacoby E, Nissani A, Levi M, Nagler A, Kubi A, et al. Head-to-head comparison of in-house produced CD19 CAR-T cell in ALL and NHL patients. J Immunother Cancer. 2020;8(1):e000148.

58. Stock S, Schmitt M, Sellner L. Optimizing Manufacturing Protocols of Chimeric Antigen Receptor T Cells for Improved Anticancer Immunotherapy. Int J Mol Sci. 2019;20(24):6223.

59. Perez C, Gruber I, Arber C. Off-the-shelf allogeneic T cell therapies for Cancer: opportunities and challenges using naturally occurring "universal" donor T cells. Front Immunol. 2020;11:583716. https://doi.org/10.3389/ fimmu.2020.583716.
60. Depil S, Duchateau P, Grupp S, Mufti G, Poirot L. Off-the-shelf' allogeneic CAR T cells: development and challenges. Nat Rev Drug Discov. 2020;19(3): 185-99. https://doi.org/10.1038/s41573-019-0051-2.

61. Ying $Z$, Huang $X F$, Xiang $X$, Liu $Y$, Kang $X$, Song $Y$, et al. A safe and potent anti-CD19 CAR T cell therapy. Nat Med. 2019;25(6):947-53. https://doi.org/1 0.1038/s41591-019-0421-7.

62. Qin H, Dong Z, Wang X, Cheng W, Wen F, Xue W, et al. CAR T cells targeting BAFF-R can overcome CD19 antigen loss in B cell malignancies. Sci Transl Med. 2019;11(511):eaaw9414.

63. Yang $\mathrm{S}$, Li J, Xu W. Role of BAFF/BAFF-R axis in B-cell non-Hodgkin lymphoma. Crit Rev Oncol Hematol. 2014;91(2):113-22. https://doi.org/10.1 016/j.critrevonc.2014.02.004.

64. Zettlitz K, Tavaré R, Tsai W, Yamada R, Ha N, Collins J, et al. F-labeled antihuman CD20 cys-diabody for same-day immunoPET in a model of aggressive B cell lymphoma in human CD20 transgenic mice. Eur J Nucl Med Mol Imaging. 2019;46(2):489-500. https://doi.org/10.1007/s00259-01 8-4214-X.

65. Pavlasova G, Mraz M. The regulation and function of CD20: an "enigma" of B-cell biology and targeted therapy. Haematologica. 2020;105(6):1494-506. https://doi.org/10.3324/haematol.2019.243543.

66. Wang $Y$, Zhang $W$, Han Q, Liu Y, Dai H, Guo Y, et al. Effective response and delayed toxicities of refractory advanced diffuse large B-cell lymphoma treated by CD20-directed chimeric antigen receptor-modified T cells. Clin Immunol (Orlando, Fla). 2014;155(2):160-75.

67. Sang W, Shi M, Yang J, Cao J, Xu L, Yan D, et al. Phase II trial of coadministration of CD19- and CD20-targeted chimeric antigen receptor T cells for relapsed and refractory diffuse large B cell lymphoma. Cancer Med. 2020;9(16):5827-38. https://doi.org/10.1002/cam4.3259.

68. Tong C, Zhang Y, Liu Y, Ji X, Zhang W, Guo Y, et al. Optimized tandem CD19/CD20 CAR-engineered T cells in refractory/relapsed B-cell lymphoma. Blood. 2020;136(14):1632-44. https://doi.org/10.1182/blood.2020005278.

69. Peng W, Paulson J. CD22 ligands on a natural N-glycan scaffold efficiently deliver toxins to B-lymphoma cells. J Am Chem Soc. 2017;139(36):12450-8. https://doi.org/10.1021/jacs.7b03208.

70. Baird JH, Frank MJ, Craig J, Patel S, Spiegel JY, Sahaf B, et al. CD22-directed CAR T-cell therapy induces complete remissions in CD19-directed CARrefractory large B-cell lymphoma. Blood. 2021;137(17):2321-5. https://doi. org/10.1182/blood.2020009432.

71. Jia H, Wang Z, Wang Y, Liu Y, Dai H, Tong C, et al. Haploidentical CD19/ CD22 bispecific CAR-T cells induced MRD-negative remission in a patient with relapsed and refractory adult B-ALL after haploidentical hematopoietic stem cell transplantation. J Hematol Oncol. 2019;12(1):57. https://doi.org/1 0.1186/s13045-019-0741-6.

72. Zeng C, Cheng J, Li T, Huang J, Li C, Jiang L, et al. Efficacy and toxicity for CD22/CD19 chimeric antigen receptor T-cell therapy in patients with relapsed/refractory aggressive B-cell lymphoma involving the gastrointestinal tract. Cytotherapy. 2020;22(3):166-71. https://doi.org/10.101 6/j.jcyt.2020.01.008.

73. Schneider D, Xiong Y, Wu D, Hu P, Alabanza L, Steimle B, et al. Trispecific CD19-CD20-CD22-targeting duoCAR-T cells eliminate antigenheterogeneous B cell tumors in preclinical models. Sci Transl Med. 2021; 13(586):eabc6401.

74. Ding S, Mao X, Cao Y, Wang N, Xu H, Zhou J. Targeting CD79b for chimeric antigen receptor T-cell therapy of B-cell lymphomas. Target Oncol. 2020; 15(3):365-75. https://doi.org/10.1007/s11523-020-00729-7.

75. Scarfò I, Ormhøj M, Frigault M, Castano A, Lorrey S, Bouffard A, et al. Anti-CD37 chimeric antigen receptor $T$ cells are active against B- and T-cell lymphomas. Blood. 2018;132(14):1495-506. https://doi.org/10.1182/blood-2018-04-842708.

76. Köksal H, Dillard P, Josefsson S, Maggadottir S, Pollmann S, Fåne A, et al. Preclinical development of CD37CAR T-cell therapy for treatment of B-cell lymphoma. Blood Adv. 2019:3(8):1230-43. https://doi.org/10.1182/bloodadvances.2018029678.

77. Xu-Monette Z, Li L, Byrd J, Jabbar K, Manyam G, Maria de Winde C, et al. Assessment of CD37 B-cell antigen and cell of origin significantly improves risk prediction in diffuse large B-cell lymphoma. Blood. 2016;128(26):3083100. https://doi.org/10.1182/blood-2016-05-715094.

78. Goodman A, Patel S, Kurzrock R. PD-1-PD-L1 immune-checkpoint blockade in B-cell lymphomas. Nat Rev Clin Oncol. 2017;14(4):203-20. https://doi. org/10.1038/nrclinonc.2016.168.

79. Song W, Zhang M. Use of CAR-T cell therapy, PD-1 blockade, and their combination for the treatment of hematological malignancies. Clin Immunol (Orlando, Fla). 2020;214:108382. 
80. Cao Y, Lu W, Sun R, Jin X, Cheng L, He X, et al. Anti-CD19 chimeric antigen receptor $T$ cells in combination with Nivolumab are safe and effective against relapsed/refractory B-cell non-hodgkin lymphoma. Front Oncol. 2019;9:767. https://doi.org/10.3389/fonc.2019.00767.

81. Tao L, Faroog M, Gao Y, Zhang L, Niu C, Ajmal I, et al. CD19-CAR-T Cells Bearing a KIR/PD-1-Based Inhibitory CAR Eradicate CD19HLA-C1 Malignant B Cells While Sparing CD19HLA-C1 Healthy B Cells. Cancers. 2020;12(9):2612.

82. Ebert L, Yu W, Gargett T, Brown M. Logic-gated approaches to extend the utility of chimeric antigen receptor T-cell technology. Biochem Soc Trans. 2018:46(2):391-401. https://doi.org/10.1042/BST20170178.

83. Han X, Wang Y, Wei J, Han W. Multi-antigen-targeted chimeric antigen receptor T cells for cancer therapy. J Hematol Oncol. 2019;12(1):128. https:// doi.org/10.1186/s13045-019-0813-7.

84. Ayyappan S, Maddocks K. Novel and emerging therapies for B cell lymphoma. J Hematol Oncol. 2019;12(1):82. https://doi.org/10.1186/s13045019-0752-3.

85. Yeku O, Brentjens R. Armored CAR T-cells: utilizing cytokines and proinflammatory ligands to enhance CAR T-cell anti-tumour efficacy. Biochem Soc Trans. 2016;44(2):412-8. https://doi.org/10.1042/BST20150291.

86. Huang R, Li X, He Y, Zhu W, Gao L, Liu Y, et al. Recent advances in CAR-T cell engineering. J Hematol Oncol. 2020;13(1):86. https://doi.org/10.1186/s13 045-020-00910-5.

87. Chmielewski M, Abken H. TRUCKs: the fourth generation of CARs. Expert Opin Biol Ther. 2015;15(8):1145-54. https://doi.org/10.1517/14712598.2015.1 046430.

88. Graham C, Jozwik A, Pepper A, Benjamin R. Allogeneic CAR-T Cells: More than Ease of Access? Cells. 2018;7(10):155.

89. Yang Y, Jacoby E, Fry T. Challenges and opportunities of allogeneic donorderived CAR T cells. Curr Opin Hematol. 2015;22(6):509-15. https://doi.org/1 $0.1097 / \mathrm{MOH} .0000000000000181$.

90. Liu D, Zhao J, Song Y. Engineering switchable and programmable universal CARs for CAR T therapy. J Hematol Oncol. 2019;12(1):69. https://doi.org/1 0.1186/s13045-019-0763-0.

\section{Publisher's Note}

Springer Nature remains neutral with regard to jurisdictional claims in published maps and institutional affiliations.

Ready to submit your research? Choose BMC and benefit from:

- fast, convenient online submission

- thorough peer review by experienced researchers in your field

- rapid publication on acceptance

- support for research data, including large and complex data types

- gold Open Access which fosters wider collaboration and increased citations

- maximum visibility for your research: over $100 \mathrm{M}$ website views per year

At $\mathrm{BMC}$, research is always in progress.

Learn more biomedcentral.com/submissions 